UNIVERSIDADE DE BRASÍLIA

Faculdade de Medicina

AVALIAÇÃO DO USO DE ENDOSCÓPIO NO SEGUIMENTO PÓS-OPERATÓRIO DE PACIENTES SUBMETIDOS À MASTOIDECTOMIA COM CAVIDADE ABERTA

GUSTAVO SUBTIL MAGALHÃES FREIRE

BRASÍLIA - DF

2015 


\section{AV ALIAÇÃO DO USO DE ENDOSCÓPIO NO SEGUIMENTO PÓS-OPERATÓRIO DE PACIENTES SUBMETIDOS À MASTOIDECTOMIA COM CAVIDADE ABERTA}

Dissertação apresentada ao Programa de Pós-Graduação em Ciências Médicas da Faculdade de Medicina da Universidade de Brasília, como requisito para obtenção do título de Mestre.

Orientador: Prof. Dr. Carlos Augusto Costa Pires de Oliveira

Coorientador: Dr. Márcio Nakanishi

BRASÍLIA - DF 
Ficha catalográfica elaborada pela Biblioteca Central da Universidade de Brasília. Acervo 1019936.

Frei re, Gustavo Subt il Magalhães.

F866a Avaliação do uso de endoscópio no seguimento pós-operatório de pacientes submetidos à mastoidectomia com cavidade aberta / Gustavo Subtil Magalhães Freire. -- 2015.

$55 \mathrm{f}$. : il. ; $30 \mathrm{~cm}$.

Dissertação (mestrado) - Universidade de Brasília, Faculdade de Medicina, 2015.

Inclui bibliografia.

Orientação: Carlos Augusto Costa Pires de Ol iveira ; Coorientação: Márcio Nakanishi .

1. Endoscopia. 2. Otorrinolaringologia. 3. Ouvidos - Cirurgia - Pacientes. I. Ol iveira, Carlos Augusto Costa Pires de. II. Nakanishi, Márcio. III. Título. 
Presidente: Prof. Dr. CARLOS AUGUSTO COSTA PIRES DE OLIVIERA Professor Orientador do Programa de Pós Graduação em Ciências Médicas Faculdade de Medicina - Universidade de Brasília

Prof. Dr. ANDRÉ LUIZ LOPES SAMPAIO

Professor - Otorrinolaringologia

Faculdade de Medicina - Universidade de Brasília

Drà. ROBERTA LEMOS VIEIRA BEZERRA

Médica Otorrinolaringologista

Hospital Universitário de Brasília - Universidade de Brasília

Drª. LUCIANA MIWA NITA WATANABE

Médica Otorrinolaringologista

Hospital de Base do Distrito Federal 


\section{AGRADECIMENTOS}

À Universidade de Brasília.

Aos pacientes pela colaboração.

Ao Prof. Dr. Carlos Augusto pela oportunidade e apoio.

Ao Dr. Márcio Nakanishi pela inspiração, apoio e orientação na medicina e na vida.

Aos amigos Daniel Michels, Rafaela Aquino e Juliana Gusmão pelo apoio e ajuda no ambulatório.

Aos Residentes que me ajudaram a identificar os pacientes elegíveis para o trabalho.

Aos meus pais por todo amor, educação, valores e pelo apoio incondicional.

À Daiana pelo carinho, companheirismo e pelas horas de sono perdidas ao meu lado fazendo revisão ortográfica.

A todos aqueles que de alguma forma me ajudaram nessa caminhada. 


\section{RESUMO}

Objetivo: Avaliar o uso de endoscópio no manejo pós-operatório de pacientes submetidos à mastoidectomia com cavidade aberta. Testar se a otoendoscopia aumenta a capacidade de inspeção e limpeza em comparação com a otomicroscopia. Desenho do estudo: Quasi-experimental. Local: Hospital terciário Hospital Universitário de Brasília. Pacientes: Pacientes em pós-operatório de mastoidectomia com cavidade aberta. Trinta e oito orelhas foram divididas em dois grupos de forma aleatória. Método: Grupo 1 - Avaliação e limpeza das cavidades mastóideas com endoscópio após limpeza com microscópio. Grupo 2 - Avaliação e limpeza das cavidades mastóideas com microscópio após limpeza com endoscópio. Foi avaliada a capacidade de exposição e limpeza de cada método, comparando o benefício de cada um quando utilizados de forma subsequente. Resultados: A endoscopia trouxe benefício adicional na exposição em $57,1 \%$ dos casos e na limpeza em $61,9 \%$. A microscopia não trouxe benefício adicional na exposição em nenhum caso. $\mathrm{Na}$ limpeza trouxe benefício em apenas $23,5 \%$ dos casos. Conclusão: O uso da otoendoscopia no cuidado pós-operatório de pacientes submetidos à mastoidectomia com cavidade aberta é eficaz. A otoendoscopia trouxe mais vantagens na exposição e limpeza do que a microscopia.

Palavras-chave: otoendoscopia, mastoidectomia, endoscópio, microscopia, colesteatoma 


\section{ABSTRACT}

Objective: To evaluate the use of ear endoscopy in the postoperative management of open mastoidectomy cavities, and to test whether ear endoscopy improves inspection and cleaning as compared with ear microscopy. Study Design: Quasiexperimental. Setting: Tertiary teaching hospital. Patients: Patients in the postoperative period of canal wall down mastoidectomy. Methods: Thirty-eight ears were randomly divided into two groups: group 1, examination and cleaning of mastoid cavities under endoscopic visualization after microscopic standard ear cleaning; group 2, examination and cleaning of mastoid cavities under microscopic visualization after endoscope-assisted ear cleaning. We assessed the ability of each method to provide exposure and facilitate cleaning, comparing the benefits of microscopy and endoscopy when used sequentially and vice-versa. Results: Endoscopy provided additional benefits for exposure in $57.1 \%$ of cases and cleaning in $61.9 \%$. Microscopy provided no additional benefits in terms of exposure in any case, and provided added benefit for cleaning in only $23.5 \%$ of cases. Conclusion: Ear endoscopy is a safe technique for the postoperative management of open mastoidectomy cavities. Ear endoscopy provided superior advantages in terms of exposure and aural cleaning as compared with microscopy.

Key words: Otoendoscopy, mastoidectomy, endoscope, microscopy, cholesteatoma 


\section{LISTA DE ABREVIATURAS E SIGLAS}

$3 \mathrm{D}$

Três dimensões

CAAE Certificado de Apresentação para Apreciação Ética

CAE Conduto auditivo externo

DFV Décio Fernandes Vanconcellos

HD High Definition

HUB Hospital Universitário de Brasília

mm Milímetros

MT Membrana timpânica

OM Orelha média

OMC Otite média crônica

TCLE Termo de Consentimento Livre e Esclarecido

W Watts

$x^{2} \quad$ Qui-quadrado 


\section{LISTA DE ILUSTRAÇÕES - FIGURAS}

Figura 1. Desenho esquemático da exposição com microscópio e diversos tipos de endoscópio. 16

Figura 2. Otoscopia de cavidade aberta esquerda com microscópio......................17

Figura 3. Pós-operatório tardio de mastoidectomia com cavidade aberta................18

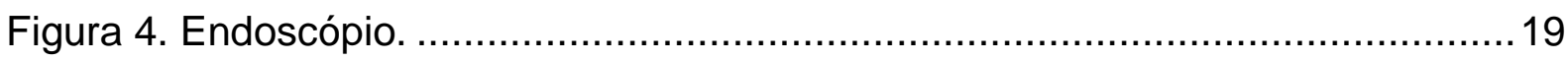

Figura 5. Otomicroscopia com paciente deitado ............................................27

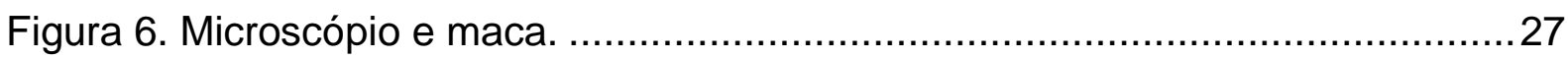

Figura 7. Otoendoscopia com paciente sentado. ............................................28

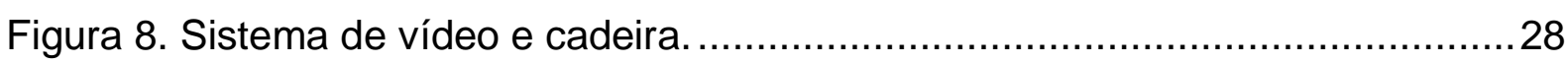

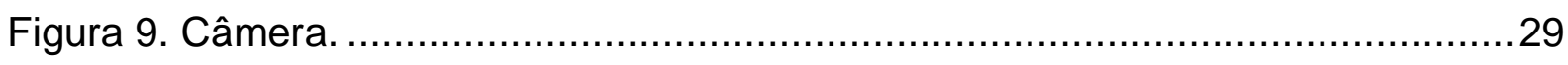

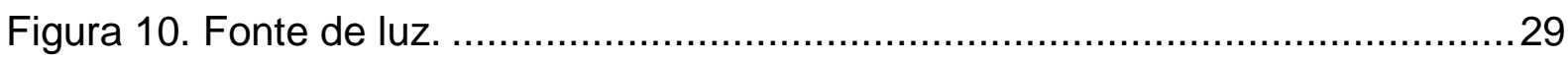

Figura 11. Material utilizado para limpeza. ..................................................... 30

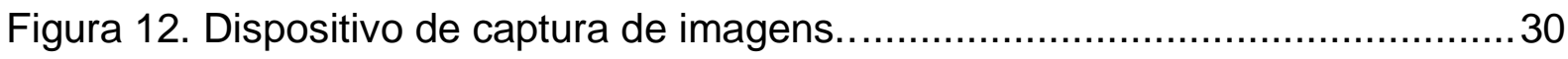

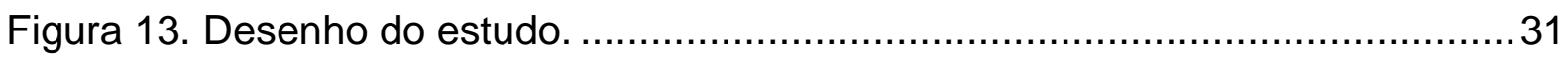

Figura 14. Inspeção e limpeza com endoscópio após microscópio ...........................40 


\section{LISTA DE ILUSTRAÇÕES - GRÁFICOS}

Gráfico 1. Avaliação do benefício do segundo método em relação à exposição. ....37

Gráfico 2. Avaliação do benefício do segundo método em relação à limpeza. .........39 


\section{LISTA DE TABELAS}

Tabela 1. Distribuição por gênero. ......................................................... 35

Tabela 2. Distribuição por lado operado. .................................................. 35

Tabela 3. Tamanho da meatoplastia, quantidade de secreção e dificuldade na limpeza.

Tabela 4. Avaliação do benefício do segundo método na exposição após inspeção e limpeza com o primeiro método. 37

Tabela 5. Avaliação do benefício do segundo método na limpeza após inspeção e limpeza com o primeiro método. 38

Tabela 6. Avaliação da relação do benefício na exposição e as variáveis 41

Tabela 7. Avaliação da relação do benefício na limpeza e as variáveis. 42 


\section{LISTA DE QUADROS}

Quadro 1. Distribuição por grupos etários. ................................................ 34

Quadro 2. Resposta dos pacientes à pergunta: "O uso dessas imagens ajudará que você aceite e siga melhor o tratamento proposto?". 


\section{SUMÁRIO}

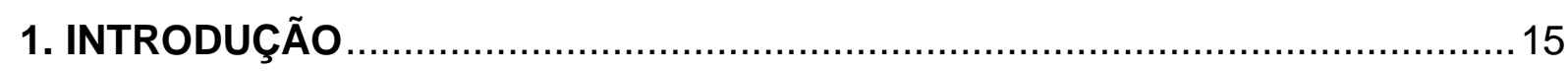

1.2 Revisão de aspectos relevantes ao tema da dissertação ................................20

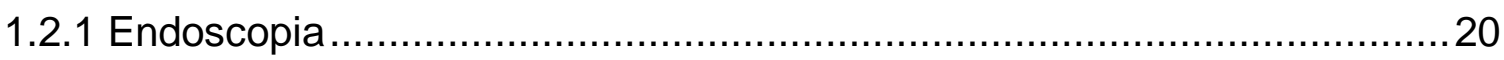

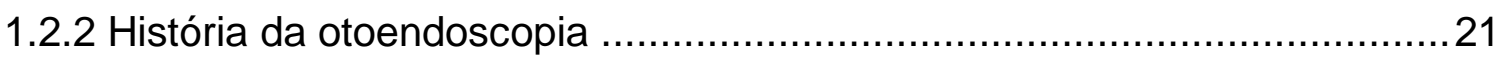

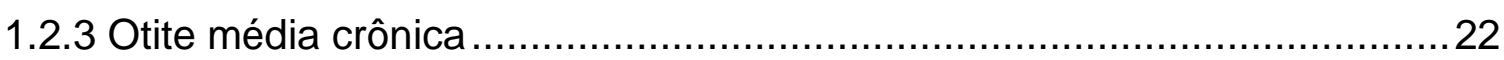

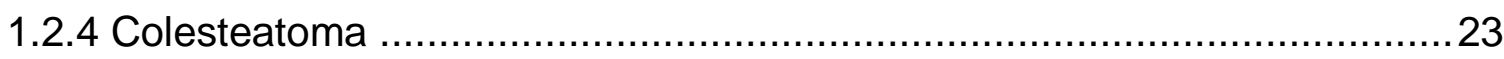

1.2.5 Tratamento cirúrgico do colesteatoma ………….............................23

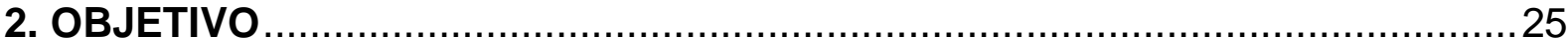

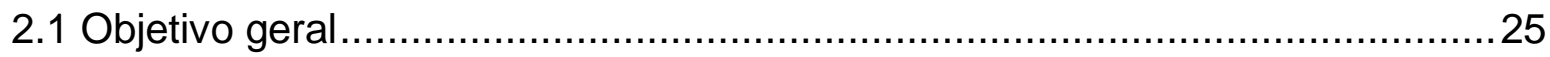

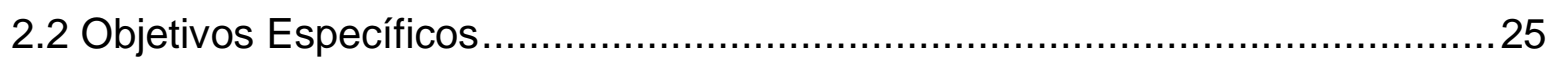

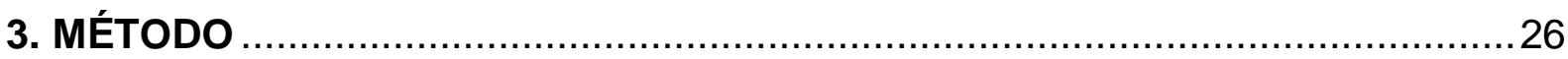

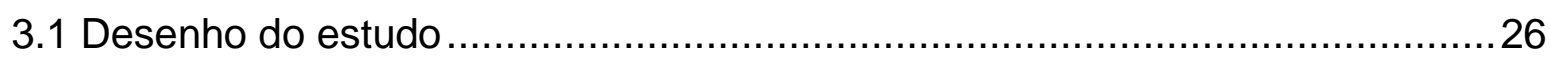

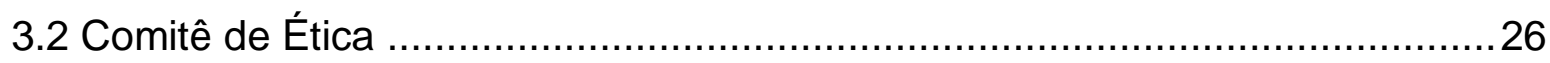

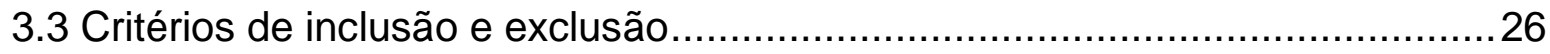

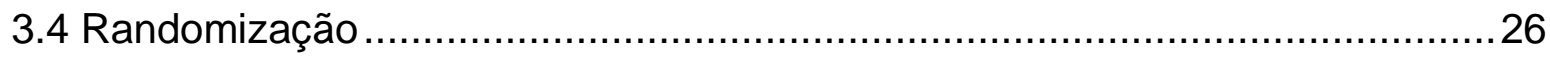

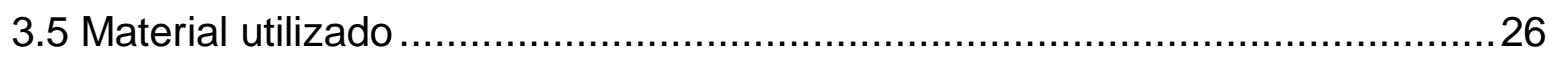

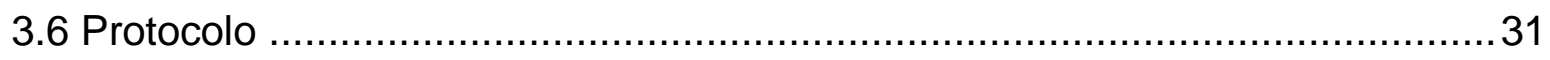

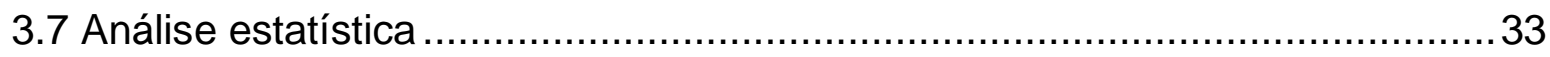

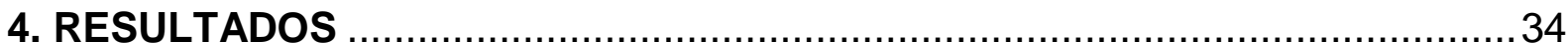

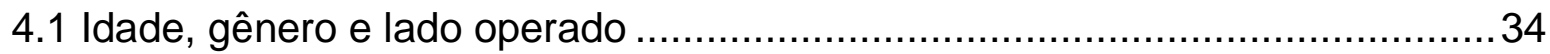

4.2 Tamanho da meatoplastia, quantidade de secreção e dificuldade na limpeza 35

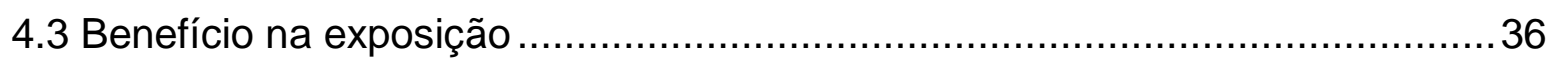

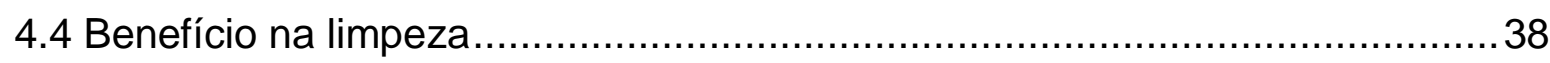

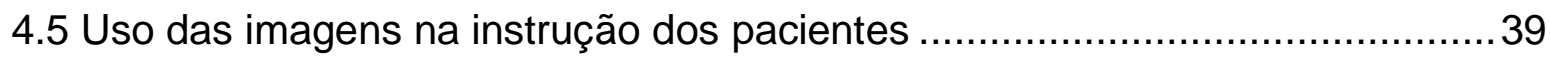

4.6 Influência das varíaveis nos desfechos primários ....................................... 41

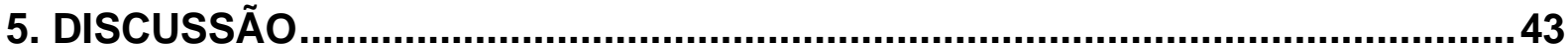

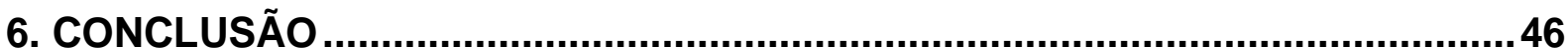

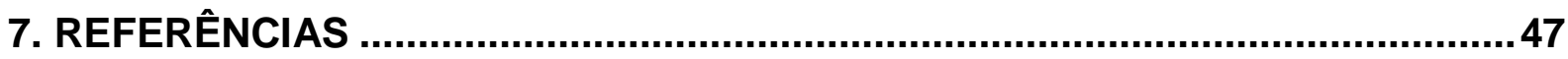

8. APÊNDICE

8.1 Apêndice 1 - Termo de Consentimento ……............................................

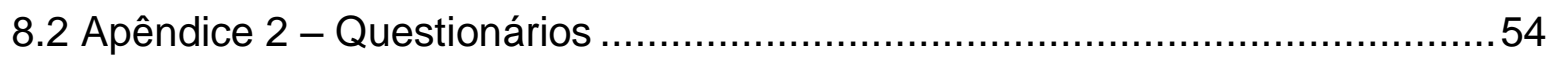




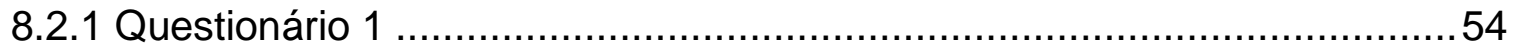

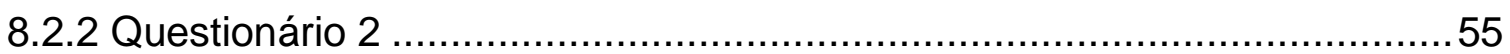

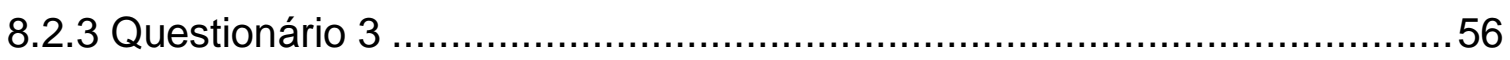




\section{INTRODUÇÃO}

Desde os primeiros relatos de avaliação endoscópica do ouvido ${ }^{1}$ em 1967, o uso de endoscópio em otologia teve um aumento progressivo. Há pelo menos duas décadas introduziu-se a endoscopia na cirurgia otológica como instrumento complementar em pacientes com colesteatoma ${ }^{2-5}$. Desde então o seu uso veio crescendo, e já é considerado instrumento de escolha por alguns cirurgiões ${ }^{2,6,7}$. Sua principal vantagem é o campo amplo de visão, que permite expor áreas inacessíveis ao microscópio ${ }^{8}$ (figura1). Isso permite uma melhor compreensão da anatomia do ouvido médio e manejo de suas doenças.

Apesar do grande interesse nos últimos anos quanto à otoendoscopia cirúrgica, a literatura médica sobre o uso de endoscópio no manejo ambulatorial pósoperatório é muito escassa. Ainda não foi determinado se seus potenciais benefícios são reais.

A importância do seguimento pós-operatório em cirurgia otológica é amplamente conhecida, especialmente em mastoidectomias com cavidade aberta quando é realizada a remoção da parede posterior do conduto auditivo externo (CAE) para comunicação da cavidade mastóidea com o CAE - em pacientes póstratamento de colesteatoma. A maioria dos pacientes necessita, em média, de 12 consultas para inspeção e limpeza de suas cavidades a cada 5 anos, o que corresponde a uma consulta a cada 5 meses $^{9}$.

A otomicroscopia atualmente é o método padrão para essa avaliação pósoperatória $^{10}$. Permite boa qualidade de imagem com possibilidade de amplificação, além de permitir que o cirurgião use as duas mãos durante a avaliação e limpeza da cavidade. Permite ainda visão binocular, o que proporciona noção de profundidade. Porém, apresenta algumas desvantagens como a baixa disponibilidade no ambiente clínico e campo de visão limitado. A baixa disponibilidade nos consultórios otorrinolaringológicos brasileiros se deve principalmente ao seu custo elevado associado ao declínio da prevalência e incidência das doenças crônicas da orelha média. O campo de visão limitado leva a uma frequente dificuldade de exposição e acesso a algumas áreas de interesse através do CAE (figuras 1, 2 e 3). É necessário 
um alinhamento entre "microscópio - abertura lateral do CAE - área de interesse", o que pode gerar alguns pontos cegos ${ }^{2,3}$. Esse alinhamento (figura 1) tende a ser mais difícil nos pacientes com CAE estreito e que apresentam algum grau de estenose em sua meatoplastia.
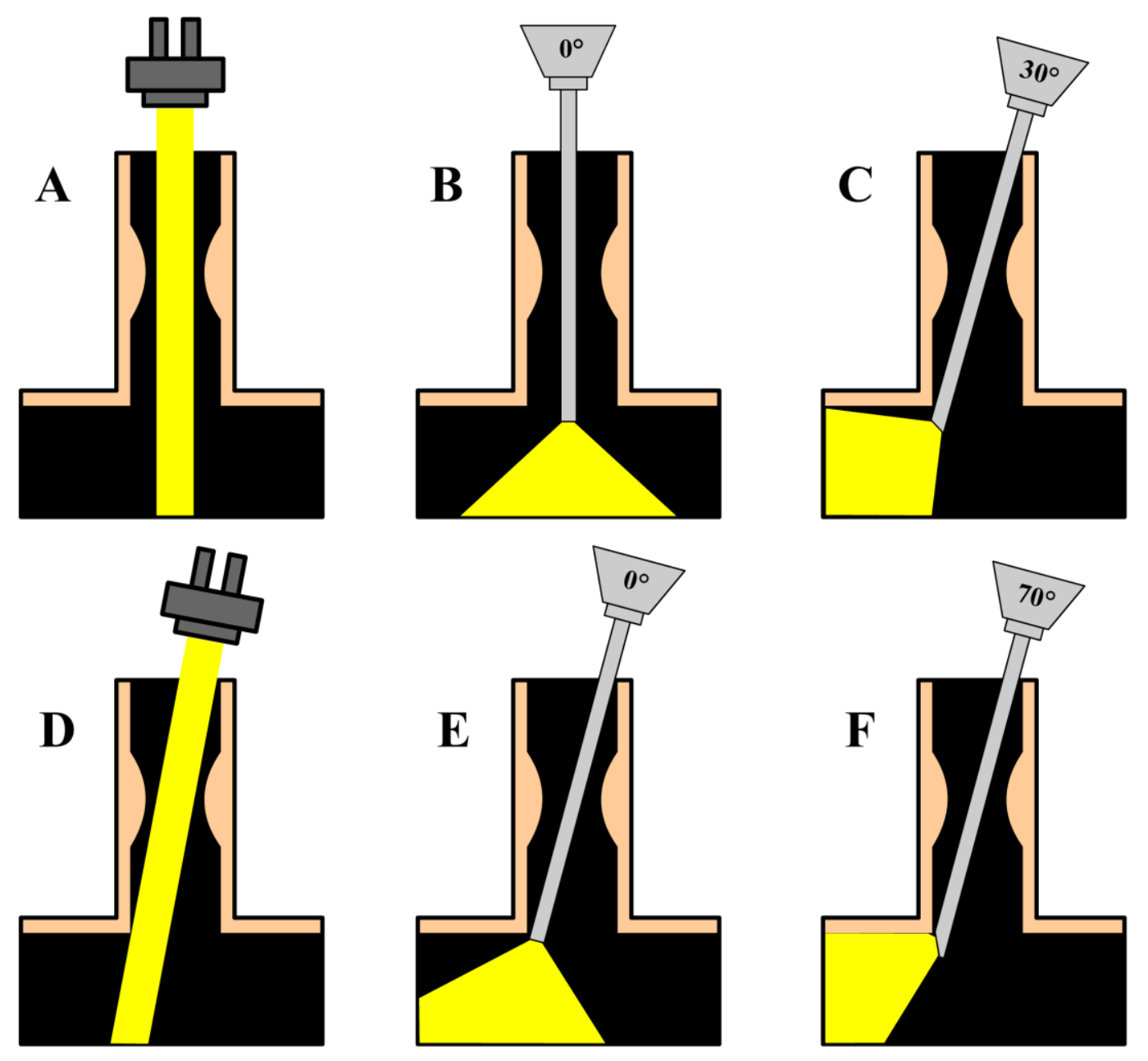

Figura 1. Desenho esquemático da exposição com microscópio $(A$ e $D)$ e diversos tipos de endoscópio ( $B, C, E$ e $F$ ). O endoscópio libera e capta luz de forma divergente a partir de sua extremidade, assim aumentando o campo de visão. Adaptado de Tarabichi M, Nogueira Junior JF, Marchioni D, Presutti L, Pothier DD, Ayache S.Transcanal Endoscopic Management of Cholesteatoma. Otolaryngologic Clinics of North America, December 2012. 
Apesar de a microscopia permitir o uso das duas mãos, frequentemente 0 examinador é obrigado a utilizar uma das mãos para manter um espéculo auricular em posição que permita o alinhamento descrito acima. Os microscópios, de forma geral, têm um limite de angulação, tornando necessário, algumas vezes, colocar o paciente e o cirurgião em posições desconfortáveis para conseguir uma boa visibilização de algumas áreas. Além disso, a cada novo posicionamento do conjunto microscópio/paciente é necessário um novo ajuste de foco, o que pode aumentar a duração do procedimento.
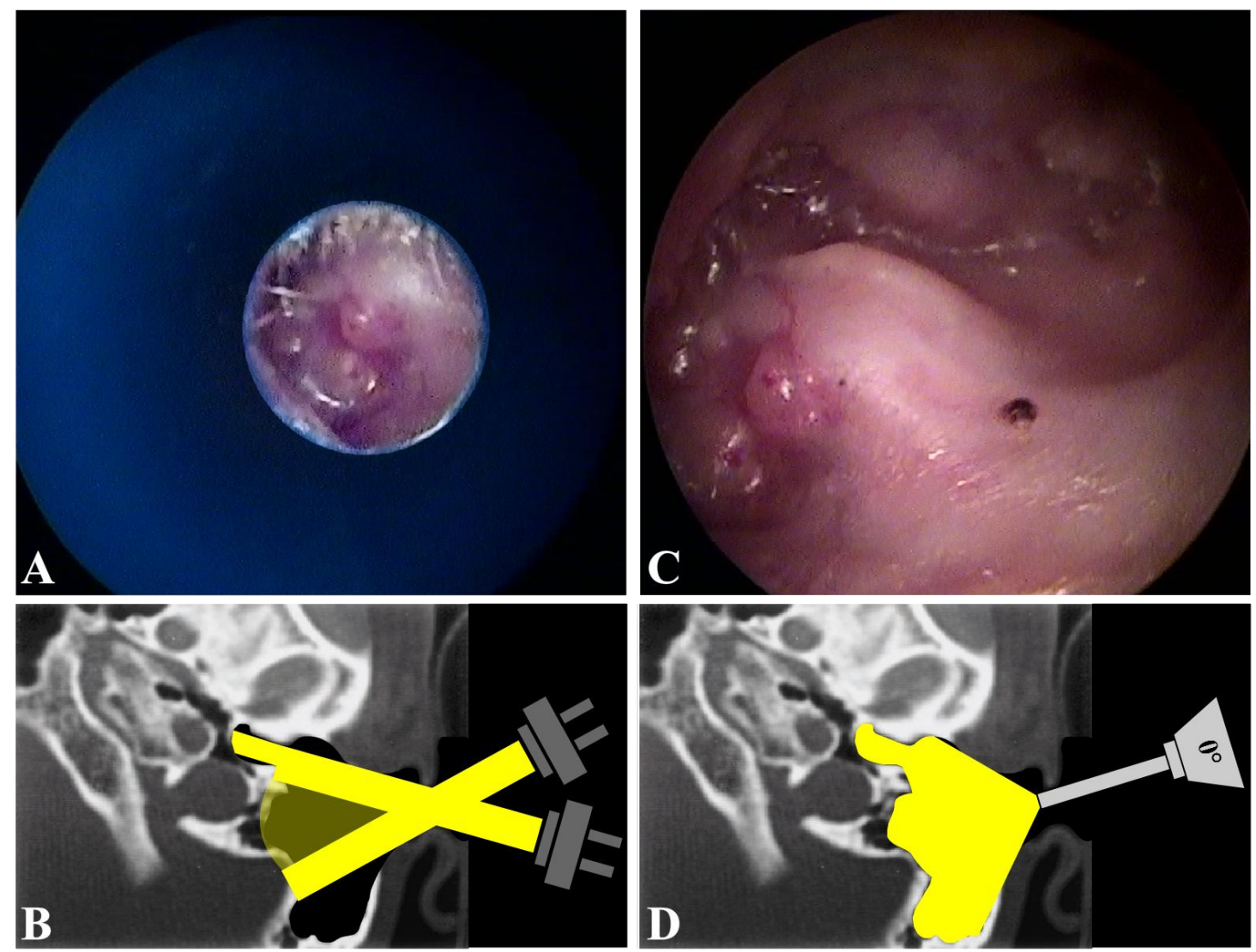

Figura 2. Otoscopia de cavidade aberta em orelha esquerda com microscópio (imagens à esquerda) e com endoscópio (imagens à direita). 


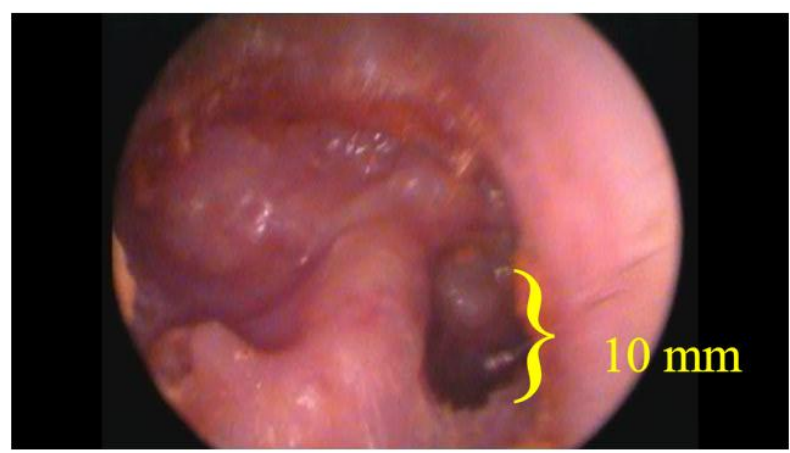

a)

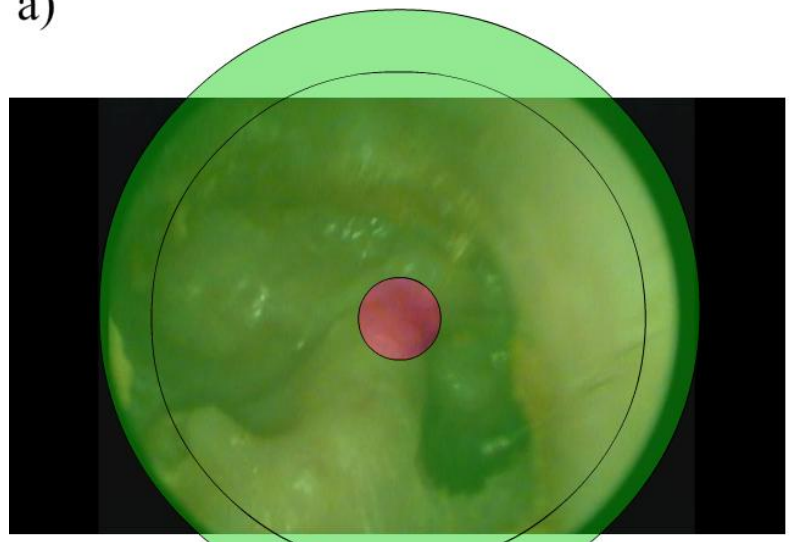

b)

c)
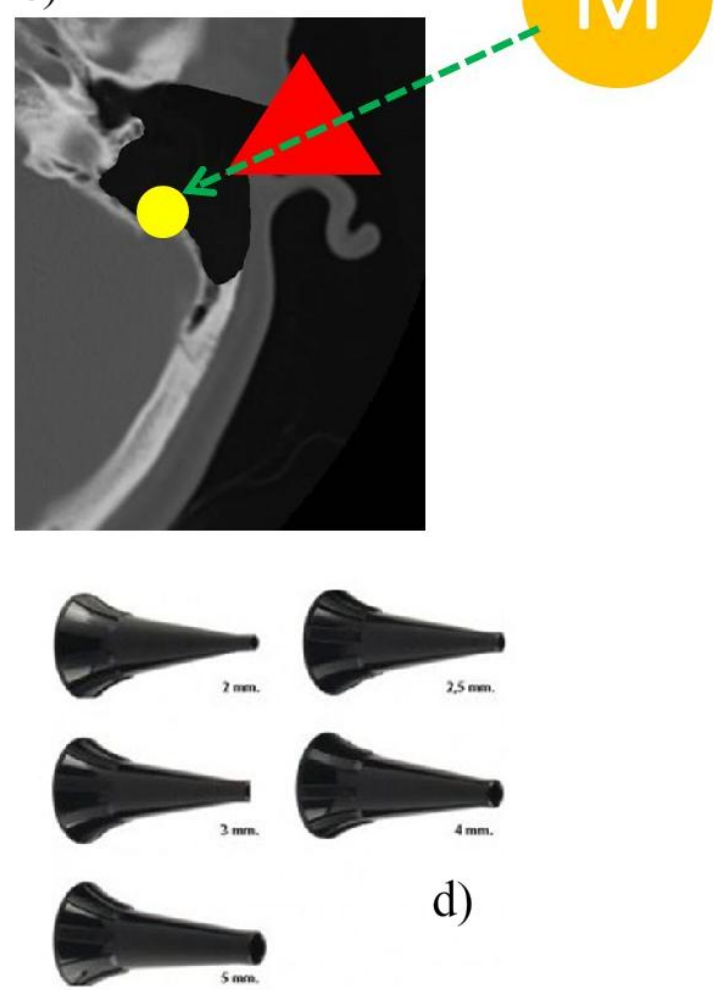

d)

Figura 3. a) Visão endoscópica de pós-operatório tardio de mastoidectomia com cavidade aberta em orelha direita. b) Simulação da visão microscópica do mesmo paciente com espéculo otológico (em verde). c) Desenho sobre tomografia de orelha esquerda simulando o alinhamento necessário para visão com microscópio $(\mathrm{M})$ e espéculo (triangulo vermelho). O círculo amarelo corresponde a um ponto de interesse dentro da cavidade. d) Espéculos auriculares de vários tamanhos.

A otoendoscopia poderia ser útil no manejo ambulatorial de pacientes com cavidade aberta. No entanto, o seu papel no manejo desses pacientes não está bem estabelecido. Muito tem se publicado em relação ao uso da otoendoscopia durante as cirurgias otológicas como método complementar e também como método substitutivo ao microscópio ${ }^{2-7}$. Porém, até o momento não há nenhuma publicação disponível no principal mecanismo de busca em literatura médica (PubMed) que trate diretamente sobre o assunto.

O campo amplo de visão do endoscópio (figura 4) permite uma avaliação mais completa da cavidade mastóidea, a despeito de estreitamentos no conduto 
auditivo externo (figuras 1 e 2). Permite assim a exposição de áreas dificilmente vistas com microscópio. O uso em si do endoscópio permite mudanças rápidas e variadas em sua angulação, o que facilita essa exposição. Além disso, o uso de endoscópios angulados aumenta ainda mais o poder de exposição de áreas estreitas $^{2}$. Outra vantagem é a grande disponibilidade dos endoscópios com sistema de vídeo, estando disponíveis na maioria dos centros de atendimento otorrinolaringológico. O endoscópio pode ser o mesmo utilizado na avaliação nasal, não exigindo aquisição de material adicional. O posicionamento, assim como o ajuste da imagem, é muito rápido, e geralmente não necessita de novos ajustes de foco durante o procedimento, o que pode significar economia de tempo. A imagem obtida é ampla, geralmente permite a exposição da cavidade como um todo, com reposicionamentos rápidos, dinâmicos e contínuos, facilitando a referência anatômica. Isso pode permitir uma melhor compreensão da anatomia e fisiologia da orelha. Com o microscópio a exposição é limitada em pequenas porções (figura 2) que são somadas umas às outras conforme os ajustes de posição e foco, que em geral são bem mais demorados que os ajustes com o endoscópio.

Uma das desvantagens da otoendoscopia é não permitir visão binocular, o que deixa a noção de profundidade prejudicada. Isso é parcialmente solucionado pelos ajustes dinâmicos que proporcionam uma noção de profundidade por meio dos reposicionamentos do endoscópio (mudança de perspectiva). Além disso, novas tecnologias, como sistemas em três dimensões (3D), têm o potencial de solucionar essa deficiência. Outra desvantagem é o comprometimento de uma das mãos, para segurar o endoscópio, restando apenas a outra para manipular outros instrumentos (aspirador e pinças). Isso pode ser minimizado com o uso de hastes articuladas de fixação de endoscópio (holders).

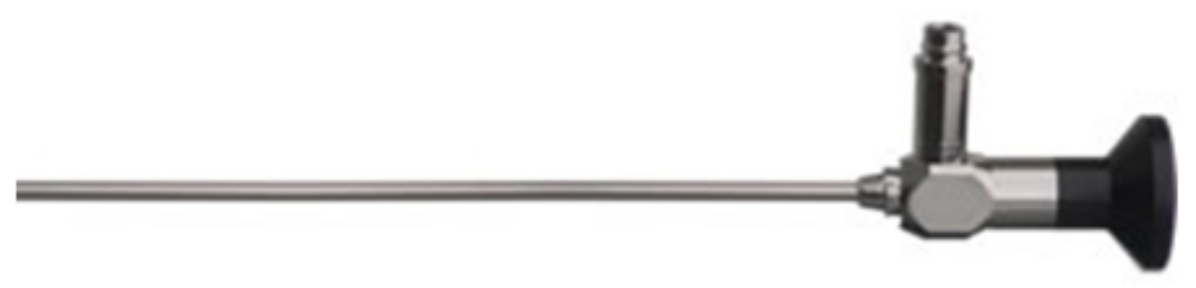

Figura 4. Endoscópio de $4 \mathrm{~mm}$ de diâmetro, $165 \mathrm{~mm}$ de comprimento e $0^{\circ}$ de angulação. 
Os sistemas de endoscopia com gravação estão amplamente disponíveis nos hospitais e consultórios otorrinolaringológicos. São utilizados na avaliação nasal e laringo-faríngea e cada vez mais vem sendo introduzidos na avaliação otológica. A facilidade de aquisição e registro de imagens torna essa ferramenta importante na educação médica e dos pacientes. Está bem estabelecido na literatura que o paciente compreende melhor a sua condição com o auxílio de imagens e dessa forma tende a aderir melhor ao tratamento ${ }^{11,12}$.

Apesar dos benefícios descritos, a otoendoscopia precisa ser avaliada para determinar o seu real papel no seguimento pós-operatório. Isso poderia proporcionar uma alternativa para avaliação dos pacientes ou mesmo uma mudança na forma de seu seguimento. Seria ainda uma boa forma de treinamento no manejo do ouvido com endoscópio.

\subsection{Revisão de aspectos relevantes ao tema da dissertação}

\subsubsection{Endoscopia}

O termo endoscopia significa "olhar dentro". De forma geral refere-se à observação interna do corpo por razões médicas com auxílio de um endoscópio (figura 4). Endoscópio é um instrumento usado para examinar o interior de um órgão oco ou uma cavidade do corpo. Diferente da maioria dos outros instrumentos médicos de imagem, os endoscópios são inseridos diretamente dentro do órgão.

Existem vários tipos de endoscópios que são utilizados amplamente nas mais variadas especialidades médicas. Eles variam principalmente em relação ao comprimento, espessura, amplitude do campo de imagem, angulação do campo de imagem e flexibilidade (rígido ou flexível)².

Dentro da otorrinolaringologia os endoscópios são utilizados no dia a dia na propedêutica e terapêutica nasal, faríngea e laríngea, seja no consultório ou no centro cirúrgico. O seu uso praticamente extinguiu a presença do microscópio em operações do nariz e dos seios paranasais. A otologia é a sub-área da otorrinolaringologia em que há a maior resistência em relação ao uso dos endoscópios. No entanto, esse quadro vem mudando progressivamente nas últimas décadas $^{2,13-42}$. 


\subsubsection{História da otoendoscopia}

Mer $^{1}$ (1967): introduziu a endoscopia da orelha média utilizando um endoscópio flexível através de MT perfuradas.

No início da década de 1980 vários autores, entre eles Hawke ${ }^{13}$, publicaram sobre o uso de endoscopia para exame do CAE e da MT.

Eichner ${ }^{14}(1981)$ tentou melhorar a visibilização da OM com endoscópio rígido de $2,7 \mathrm{~mm}$.

Nomura $^{15}$ (1982) foi o primeiro a introduzir um endoscópio através de uma miringotomia (incisão na MT).

Takahashi e colaboradores $^{16}$ (1990) realizaram endoscopia da orelha média durante a colocação de tubos de ventilação em pacientes com otite média com efusão. Avaliaram 26 orelhas e descreveram as características da mucosa (edema em $73,1 \%$ e hiperemia em $23,1 \%$ dos casos) e do óstio timpânico da tuba auditiva (estenosada em $33,3 \%$ dos casos e preenchida por efusão em $25 \%$ dos casos) durante a fase ativa da doença.

Thomassin e colaboradores $^{17}$ (1993) iniciaram o uso da otoendoscopia de forma complementar em mastoidectomias com objetivo de avaliar e evitar colesteatomas residuais. Desenvolveram então um grupo de instrumentos para ser utilizado em otoendoscopia cirúrgica.

Poe e colaboradores ${ }^{18}$ (1994) usaram endoscopia trans-timpânica para confirmação de fístula perilinfática e identificação de outras condições patológicas da orelha média.

Badr-el-Dine $^{19}$ (2002) e El-Messelaty ${ }^{3}$ (2003) publicaram sobre o papel da endoscopia com método complementar na cirurgia do colesteatoma. Documentaram a grande redução no risco de recorrência quando utilizado o endoscópio.

Yung $^{20}$ (2001) e Ayache ${ }^{21}$ (2008) também publicaram sobre a redução de colesteatoma residual quando utilizado o endoscópio.

Abdel Baki e colaboradores ${ }^{22}$ (2002) publicaram sobre o uso da otoendoscopia para avaliar a presença de doença no seio timpânico. 
Mattox $^{23}$ (2004) publicou uma série de cinco casos com uso complementar de endoscopia em operações de doenças do ápice petroso (4 granulomas de colesterol e 1 colesteatoma).

Kakehata $^{24-26}$ (2004 e 2005) publicou seus resultados sobre a utilização de otoendoscopia na avaliação de pacientes com perda auditiva condutiva e de retrações da membrana timpânica (bolsas de retração). No ano seguinte (2006) publicou seus primeiros resultados sobre timpanoplastia endoscópica com sucesso em 9 pacientes.

Magnan $^{27}$, Sanna ${ }^{27}$, Bader-el-Dine ${ }^{28,29}$, El-Garem ${ }^{30}$ (2002) fizeram uma série de publicações sobre suas experiências no uso da endoscopia em procedimentos neuro-otológicos (da base lateral do crânio). Eles publicaram a experiência em 80 casos de descompressão do nervo facial no ângulo ponto-cerebelar pela via retrosigmoidea com uso adjuvante de endoscopia, 42 casos de descompressão do nervo trigêmeo em casos de neuralgia, e a experiência em geral sobre o tema.

McKennan $^{31}$ (1993) descreveu a inspeção endoscópica em segundo tempo ("second-look") de cavidades mastóideas na procura de colesteatoma residual. Para isso utilizou uma pequena incisão retroauricular.

Presutti e colaboradores $^{32}$ (2008) publicaram suas experiências sobre o uso complementar de endoscopia em 32 operações para tratamento de colesteatoma.

Marchioni e colaboradores $^{33}$ (2008) publicaram os resultados da abordagem endoscópica transcanal primária de 21 pacientes com colesteatoma.

Nogueira $^{7}$ (2011) publicou resultados preliminares de estapedotomias totalmente endoscópicas.

Tarabichi e colaboradores ${ }^{2,6,34-42}$ (entre 1997 e 2013) publicaram pelo menos onze trabalhos descrevendo o uso da endoscopia em operações transcanais da orelha média, abordagem de colesteatoma e anatomia cirúrgica endoscópica.

\subsubsection{Otite média crônica}

Otite média crônica (OMC) é definida como uma condição inflamatória da orelha média $(\mathrm{OM})$ associada à perfuração ampla da membrana timpânica (MT) e à 
otorréia, que se mantém por pelo menos 12 semanas (Proctor, 1973) ${ }^{43}$. Está associada a alterações histológicas irreversíveis (Paparela, 1983). Em 1970, Paparella e colaboradores ${ }^{44}$ propuseram a teoria do "continuum" para explicar a patogênese das otites médias. De acordo com essa teoria ocorreria uma série de eventos sequenciais com comprometimento do fluxo de gases entre a mastóide, orelha média e a tuba auditiva. Dessa forma partiria-se de uma otite média serosa ou purulenta e, com a manutenção das condições adversas à orelha média, ocorreriam alterações progressivas do epitélio até o ponto em que se tornariam irreversíveis. A otite média serosa ou purulenta se transformaria em seromucóide, mucóide e então crônica. Estudos histopatológicos encontraram alteração na cadeia ossicular (reabsorção) em 96\% dos ossos temporais com OMC avaliados ${ }^{45}$.

A OMC pode ser dividida em OMC sem colesteatoma e OMC com colesteatoma. A diferença entre os dois subtipos é a presença do colesteatoma, que aumenta a agressividade da doença.

\subsubsection{Colesteatoma}

Colesteatoma é um cisto de inclusão epidérmica na orelha média ou cavidade mastóidea. Ele contém debris celulares provenientes de descamação (principalmente queratina) de seu epitélio escamoso queratinizado. Foi descrito como um tumor perolado do osso temporal por J. Cruveilhier ${ }^{46}$ em 1828. O termo colesteatoma foi criado por Muller $^{47}$ em 1838 e tinha relação com o termo "colesterol". A criação do nome foi um equívoco, pois esta entidade não contém colesterol, mas sim flocos de queratina que, grosseiramente, se parecem com cristais de colesterol. Os colesteatomas podem ser congênitos ou adquiridos. Os adquiridos podem ser primários (surgem por formação de bolsa de retração da MT em direção à $O M$ devido à pressão negativa gerada por obstrução da via de aeração) ou secundários (por migração de epitélio queratinizado para dentro da OM através de uma perfuração da MT).

\subsubsection{Tratamento cirúrgico do colesteatoma}

A única maneira de erradicar um colesteatoma da $\mathrm{OM}$ é através de abordagem cirúrgica. A extensão da abordagem e decisão em operar o paciente leva em consideração os seguintes fatores: natureza e extensão da doença, existência de complicações, grau de pneumatização da mastóide, função da tuba 
auditiva, estado da audição das duas orelhas e habilidade do cirurgião ${ }^{48}$. Dentre as várias características da operação, deve-se optar por uma mastoidectomia com cavidade fechada ou aberta. A técnica fechada consiste na remoção do trabeculado ósseo da mastóide (células aéreas) criando dessa forma uma cavidade única que deve estar comunicada com a OM. Na técnica aberta adiciona-se a remoção da parede posterior do conduto auditivo externo (CAE) para comunicar a cavidade mastoidea com a luz do CAE. As duas técnicas tem suas vantagens e desvantagens. A técnica aberta tem como vantagens melhor exposição para a remoção da doença, menor taxa de recorrência, porém exige mais cuidados no seguimento pós-operatório (que em média demandará cuidados a cada 5 meses para o resto da vida). Já a técnica fechada pode permitir uma menor destruição da anatomia do osso temporal e um pós-operatório menos oneroso, porém tem maiores taxas de recidiva e necessidade de reintervenções ${ }^{49-51}$.

A operação é realizada tradicionalmente com auxílio de microscópio cirúrgico. Nas últimas décadas tem-se adicionado o uso do endoscópio como ferramenta complementar nessas operações ${ }^{2-5}$. 


\section{OBJETIVO}

\subsection{Objetivo geral}

Avaliar o uso de endoscópio no manejo pós-operatório de pacientes submetidos à mastoidectomia com cavidade aberta.

\subsection{Objetivos Específicos}

Avaliar por meio de questionários se a otoendoscopia aumenta a capacidade de inspeção e limpeza em comparação com a otomicroscopia.

Avaliar a influência sobre o benefício na exposição e limpeza das variáveis: tamanho da meatoplastia, quantidade de material na cavidade a ser removido e dificuldade encontrada na inspeção e limpeza.

Avaliar se o uso de imagens, adquiridas da orelha cada paciente, pode auxiliar na educação dos pacientes sobre a própria doença. Avaliar se o uso das imagens tem influência na compreensão sobre a doença e na aderência ao tratamento. 


\section{MÉTODO}

\subsection{Desenho do estudo}

Trata-se de um estudo prospectivo, quasi-experimental realizado no Ambulatório de Otorrinolaringologia do Hospital Universitário de Brasília (HUB). O estudo só não foi considerado um ensaio clínico randomizado devido à modalidade de randomização utilizada (detalhada no item 3.4). Foram incluídos pacientes que fazem seguimento regular no ambulatório de otologia, mediante a assinatura do termo de consentimento livre e esclarecido (apêndice 1). Os pacientes foram avaliados de janeiro a julho de 2014.

\subsection{Comitê de Ética}

Este estudo foi avaliado e aprovado pelo Comitê de Ética em Pesquisa da Faculdade de Medicina da Universidade de Brasília (Certificado de Apresentação para Apreciação Ética - CAAE: 13512613.5.0000.5558).

\subsection{Critérios de inclusão e exclusão}

Os critérios de inclusão foram: idade entre 18 e 70 anos; realização de timpanomastoidectomia com cavidade aberta há pelo menos 60 dias; presença de crostas/debris/secreção em cavidade mastóidea e/ou ouvido médio a serem removidas. Critérios de exclusão: presença de complicações cirúrgicas como paralisia facial, meningite, fístula liquórica, fístula perilinfática.

\subsection{Randomização}

Os pacientes foram divididos em dois grupos de forma aleatória. Durante três meses consecutivos todos os pacientes que compareceram espontaneamente ao ambulatório para consulta (que eram elegíveis e que aceitaram participar do estudo) foram alocados no grupo 1. Nos três meses seguintes o mesmo ocorreu para o grupo 2. Dessa forma, mesmo havendo alocação aleatória por período consecutivo de tempo, a amostra deve ser considerada de conveniência.

\subsection{Material utilizado}

A avaliação sob microscopia foi realizada com o paciente deitado (figura 5) e com microscópio óptico do fabricante DFV (figura 6). A avaliação sob endoscopia foi 
realizada com o paciente sentado (figura 7 e 8) com endoscópio Karl Storz ( $4 \mathrm{~mm}$, $165 \mathrm{~mm}, 0^{\circ}$ ), câmera analógica Astus Visun (figura 9) e fonte de luz de halógena 250 W Ferrari (figura 10). As pinças e os aspiradores foram os mesmos utilizados rotineiramente sob microscopia (figura 11). As imagens foram gravadas em um computador com auxílio de um dispositivo de captura (Pinnacle Studio MovieBox) e do software Pinnacle Studio versão 14 (figura 12).

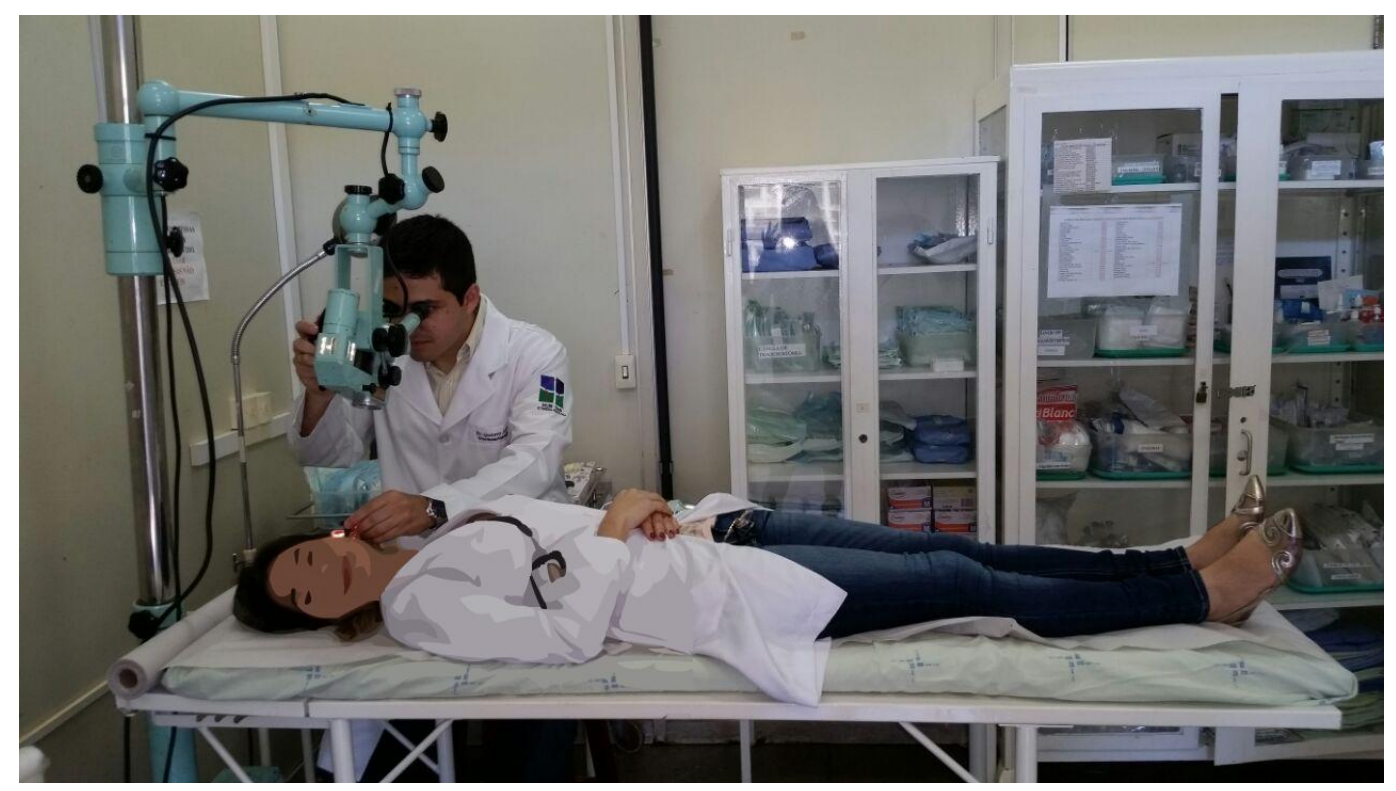

Figura 5. Otomicroscopia com paciente deitado.

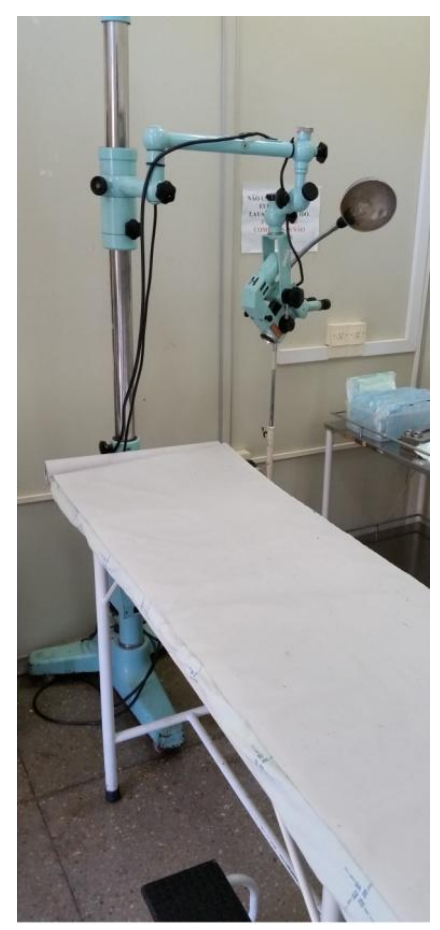

Figura 6. Microscópio e maca. 


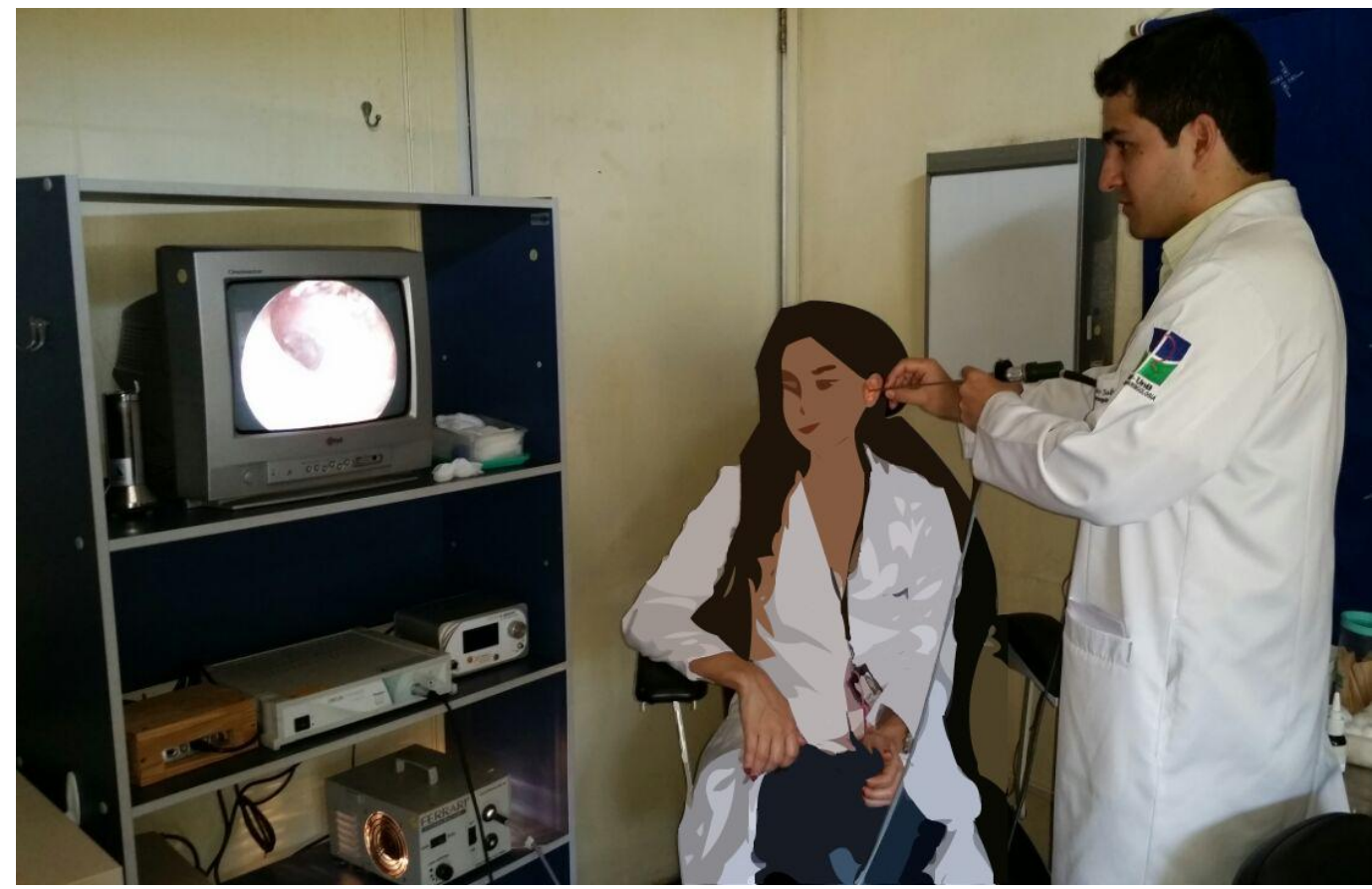

Figura 7. Otoendoscopia com paciente sentado.

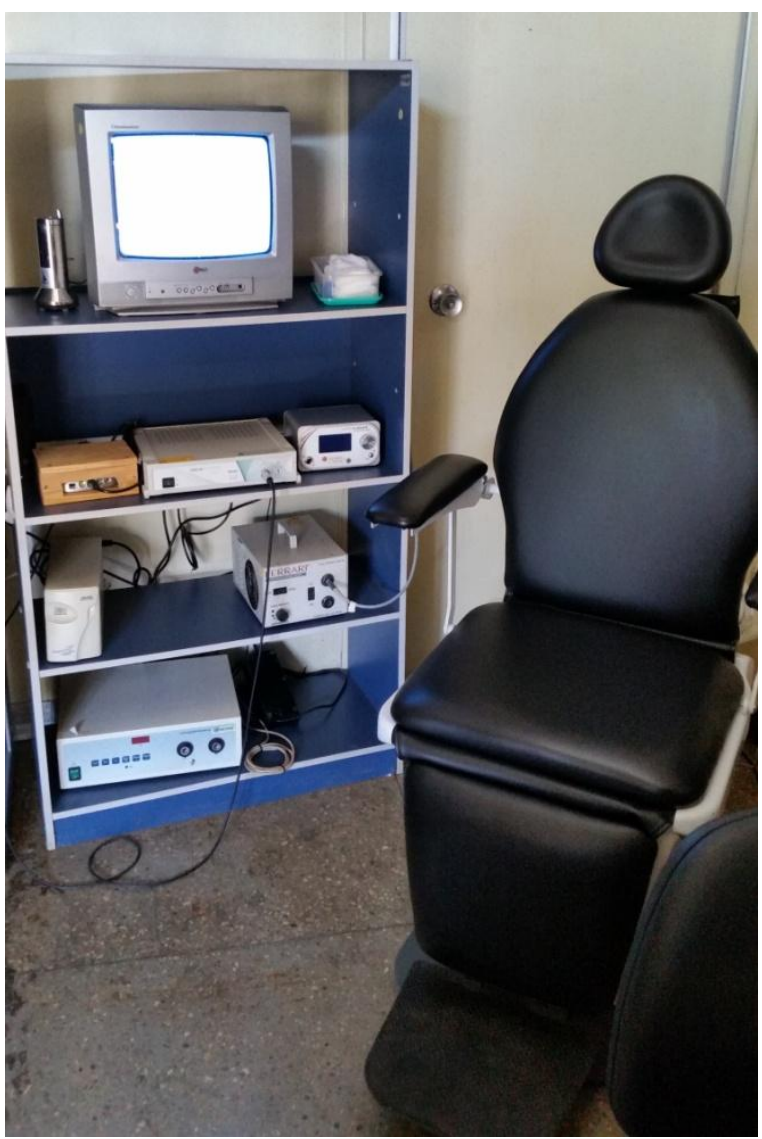

Figura 8. Sistema de vídeo e cadeira adequada para exame otorrinolaringológico. 


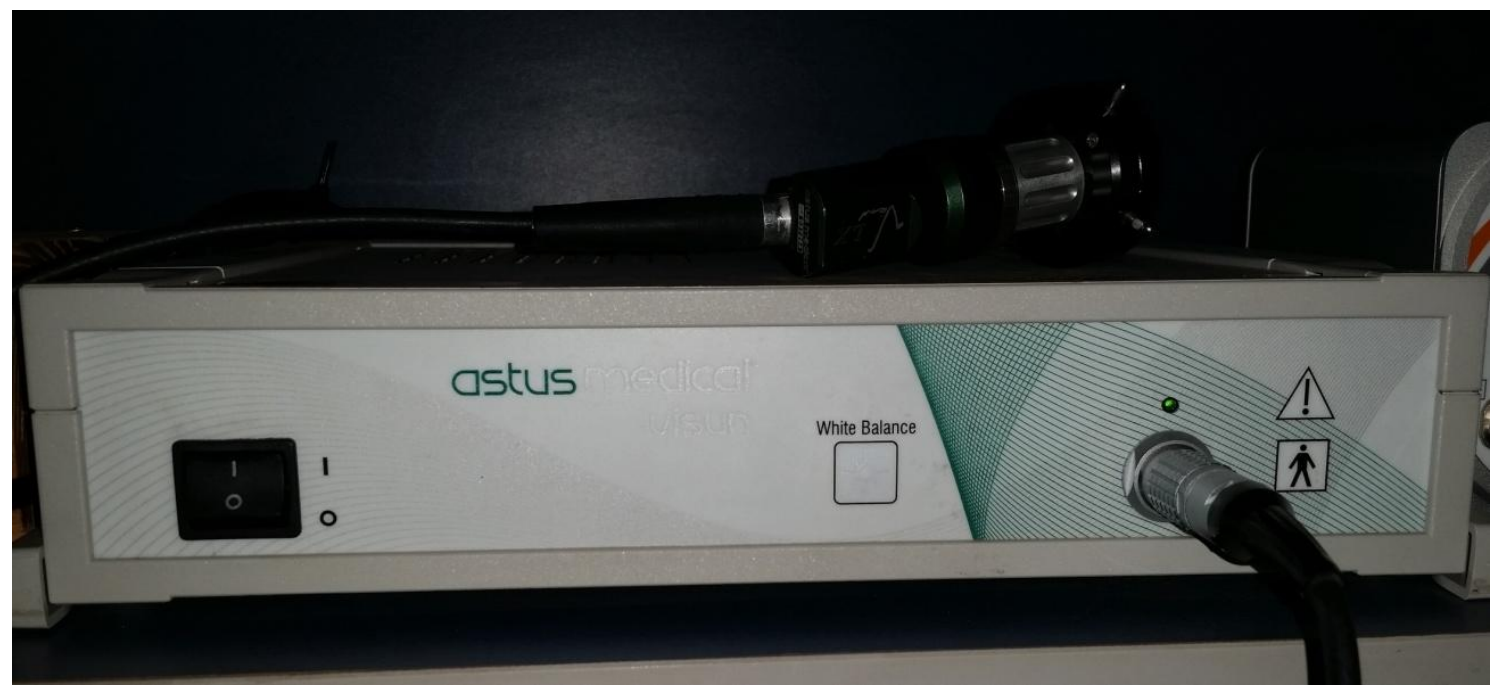

Figura 9. Câmera analógica utilizada no estudo.

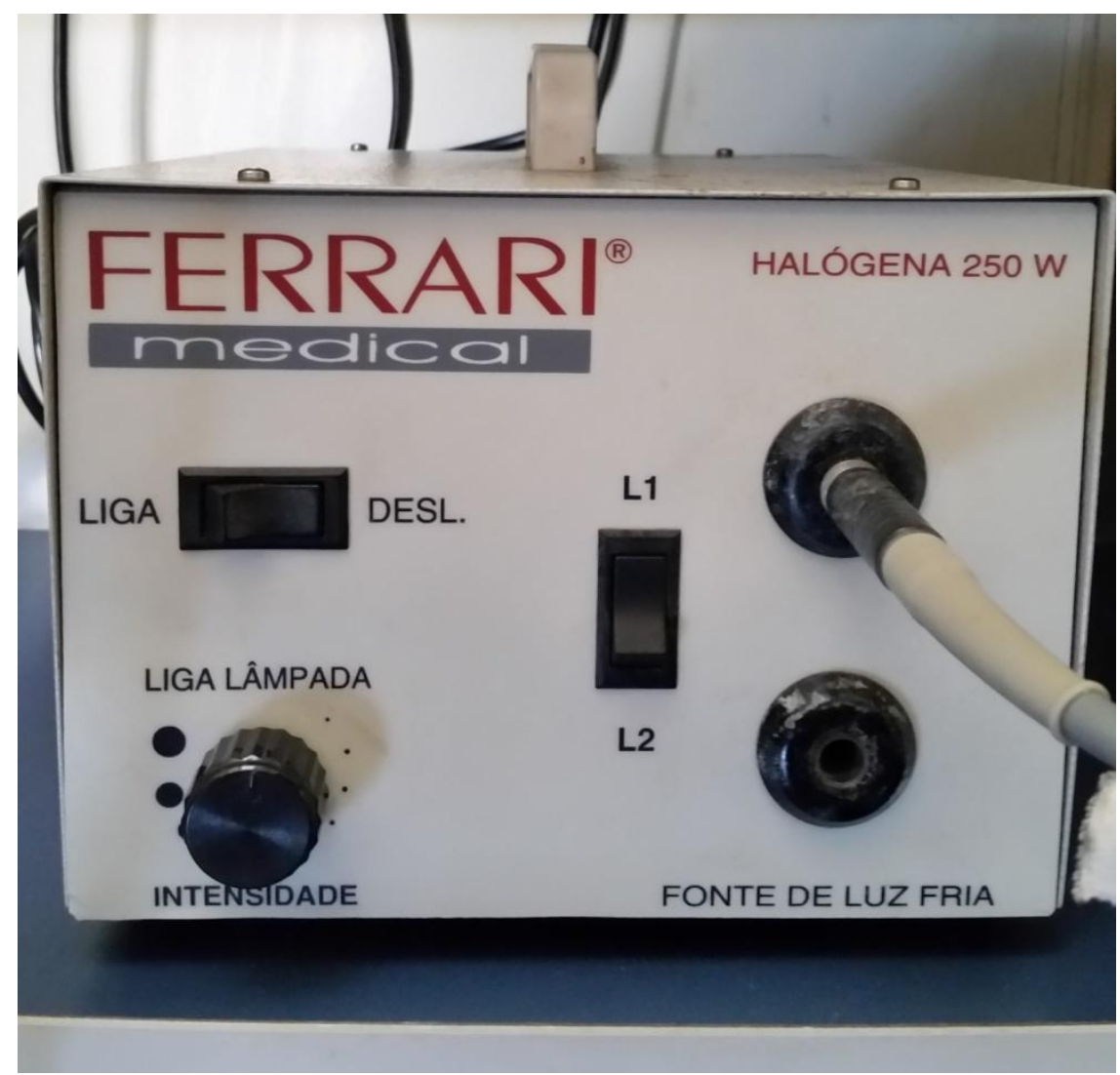

Figura 10. Fonte de luz halógena $250 \mathrm{~W}$. 


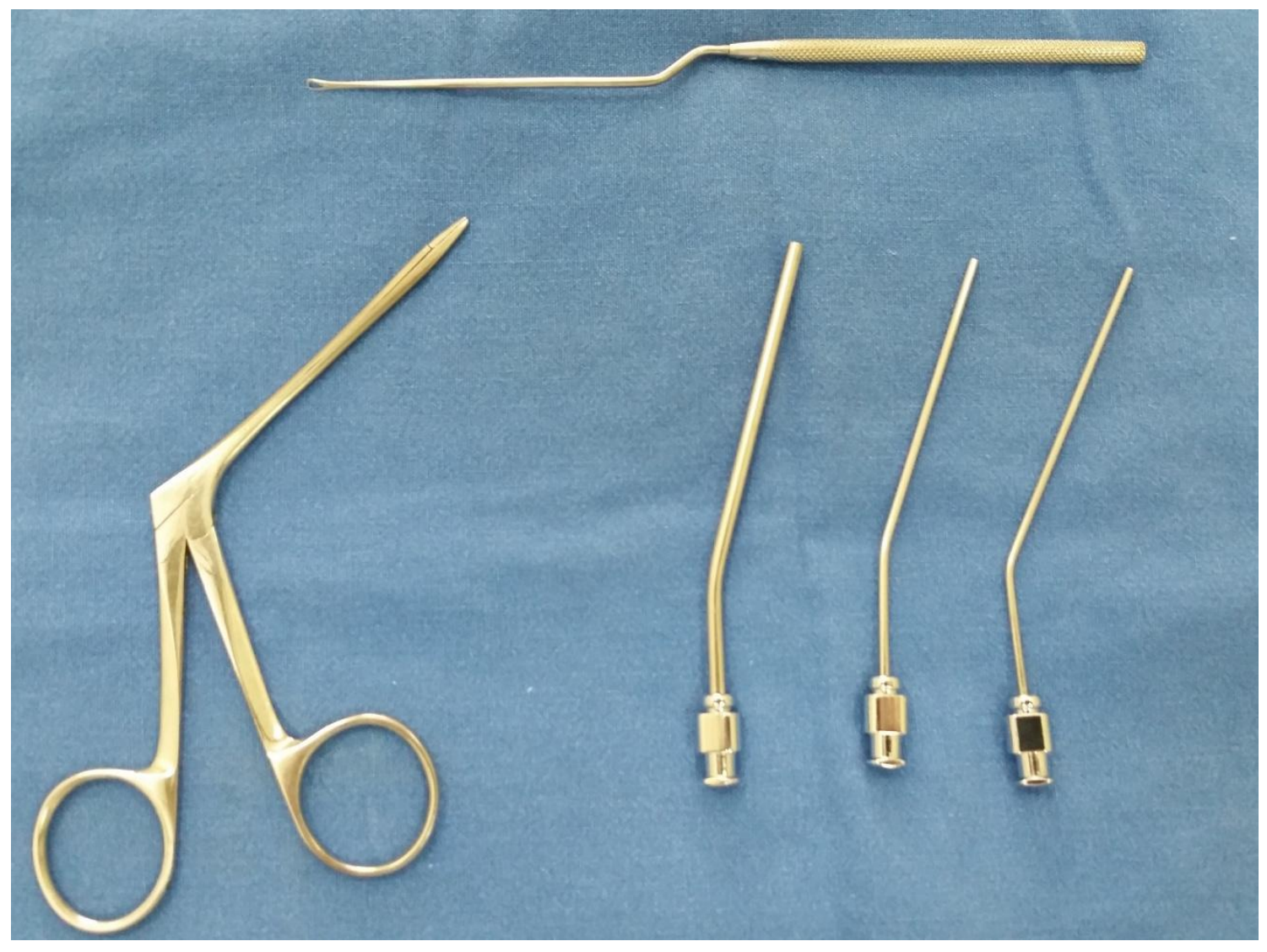

Figura 11. Material utilizado para limpeza: pinça jacaré, cureta baioneta e aspiradores.

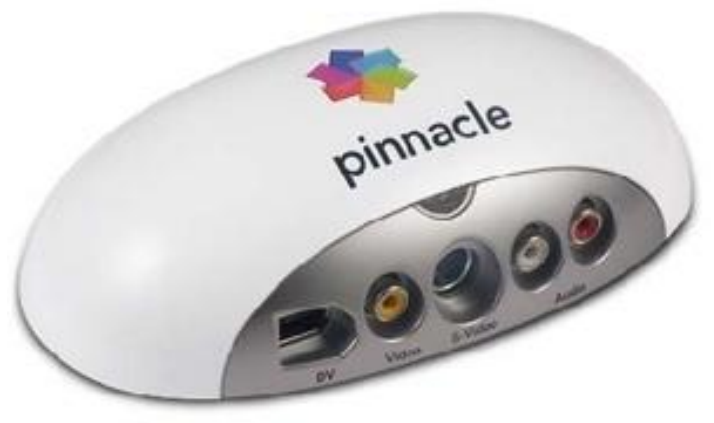

Figura 12. Dispositivo de captura de imagens. 


\subsection{Protocolo}

No grupo 1, os pacientes receberam o atendimento habitual com avaliação e limpeza sob otomicroscopia por um avaliador cego (fellow em otologia) em relação aos objetivos do trabalho. A figura 13 resume o desenho do estudo. O examinador respondeu o questionário 1 (apêndice 2) com objetivo principal de avaliar a presença de material na cavidade, a capacidade de exposição da cavidade, a capacidade de limpeza, as características da meatoplastia (estreita/estenosada, ampla ou muito ampla).

A seguir o paciente foi avaliado por outro examinador (fellow em rinologia) que fez a inspeção através de otoendoscopia. Caso ainda apresentasse algum material a ser removido, a limpeza adicional foi realizada sob otoendoscopia. Todo o procedimento sob otoendoscopia foi gravado. Os Fellows são otorrinolaringologistas recentemente formados que atuam em uma área específica dentro do Hospital Universitário em um programa de subespecialização.

Grupo 1

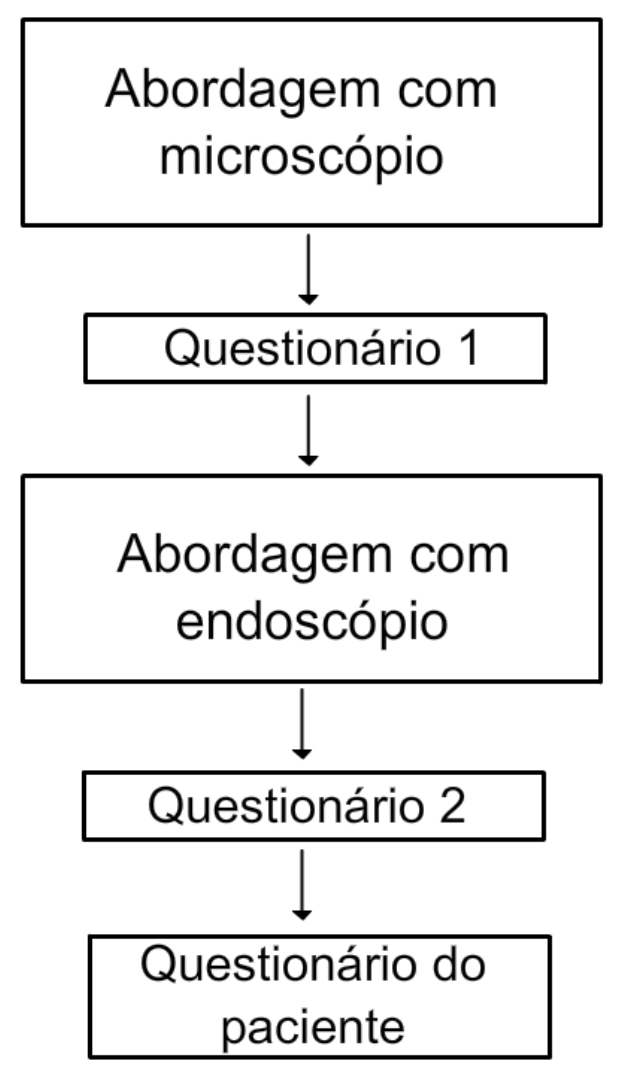

Grupo 2

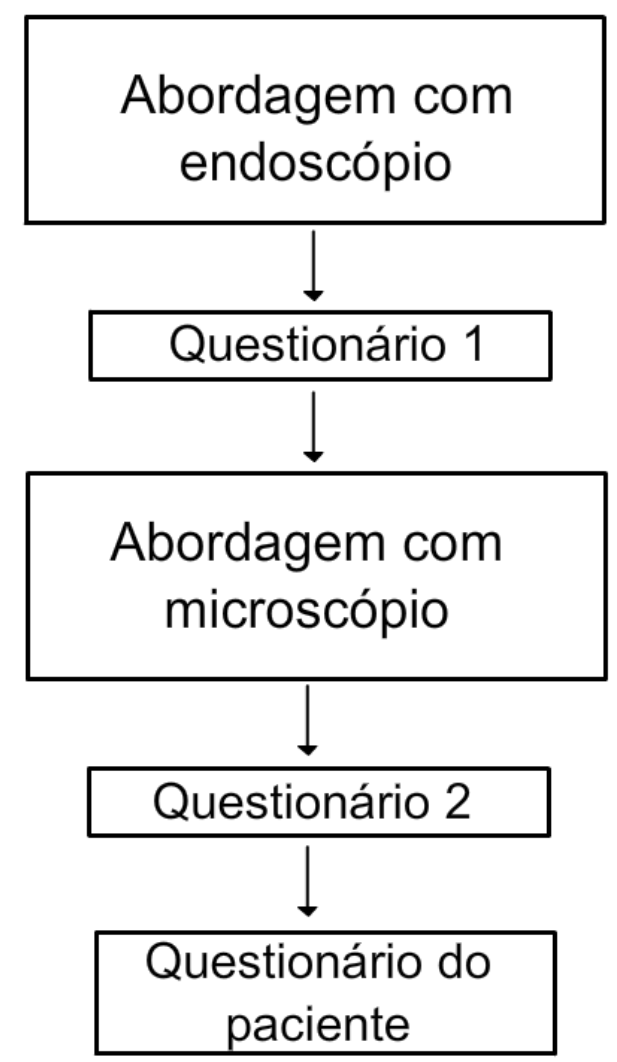

Figura 13. Desenho do estudo. 
Esse segundo examinador respondeu o questionário 2 (apêndice 2), com objetivo principal de avaliar a capacidade de exposição da cavidade, a presença de material remanescente da primeira limpeza e a capacidade de limpeza.

Em relação à quantidade de material presente na cavidade foi considerado 0 seguinte: grande quantidade - mais de $50 \%$ da cavidade preenchida; moderada quantidade - entre 25 e $50 \%$ da cavidade preenchida; e pequena quantidade menos de $25 \%$ da cavidade preenchida.

Cada paciente recebeu explicações sobre a sua condição com auxílio das imagens adquiridas em sua otoendoscopia. Em seguida respondeu o questionário 3 (apêndice 2) com objetivo de avaliar a percepção do paciente sobre o impacto das imagens na sua compreensão da doença e na aderência ao seguimento.

No grupo 2 ocorreu o inverso. Os pacientes fizeram avaliação e limpeza sob otoendoscopia (fellow em rinologia) e em seguida foram avaliados sob microscopia (fellow em otologia), seguindo o preenchimento os mesmos questionários (figura 5).

Para análise dos resultados (exposição e limpeza da cavidade) foram considerados os benefícios proporcionados pelo segundo método de avaliação em relação ao primeiro. Ou seja, após a abordagem com microscópio foi avaliado se houve uma melhor exposição ou limpeza com o endoscópio (grupo 1).

Por exemplo, quando houve exposição e limpeza completas com microscópio seguidas de exposição e limpeza completas com endoscópio, conclui-se que o segundo método não apresentou benefício em relação ao primeiro. Já quando a abordagem for considerada incompleta com o microscópio e completa com o endoscópio, o segundo método apresentou benefício em relação ao primeiro. Quando o primeiro examinador considerou a limpeza completa, mas o segundo examinador encontrou material a ser removido, conclui-se que houve benefício na exposição e na limpeza.

No grupo 2 foi feita a mesma análise seguindo a ordem dos examinadores e questionários. Então os resultados dos grupos foram comparados na procura de diferenças entre eles. Foi também avaliado o impacto das demais variáveis (tamanho da meatoplastia, quantidade de material a ser removido e dificuldade encontrada) nos resultados. 


\subsection{Análise estatística}

Todas as variáveis do estudo eram categóricas. Foi testado se cada variável (tamanho da meatoplastia, quantidade de secreção, dificuldade na limpeza) teve alguma influência nos desfechos primários (benefício na exposição e benefício na limpeza). Além disso, foi avaliada a presença diferenças entre os grupos em cada variável. Foi testado se havia independência entre duas variáveis cruzadas, sendo que o cálculo utilizado foi a estatística da aderência aproximada a distribuição de Qui-quadrado $(x 2)$. Os resultados foram considerados estatisticamente significantes quando o valor de $p$ foi menor do que 0,05 . Todos os testes foram realizados utilizando o software SPSS versão 20. 


\section{RESULTADOS}

\subsection{Idade, gênero e lado operado}

Foram incluídas 38 orelhas no estudo. A idade dos pacientes variou entre 18 e 70 com média de idade de 39,3 anos (quadro 1). O grupo 1 teve uma amostra de 21 orelhas, sendo 12 masculinas e 9 femininas. O grupo 2 teve uma amostra de 17 orelhas, sendo 6 masculinas e 11 femininas. Foram 13 orelhas direitas e 8 esquerdas no grupo 1, e 8 direitas e 9 esquerdas no grupo 2. Não houve diferença estatística entre os grupos em relação a essas variáveis (tabela 1 e 2).

Quadro 1. Distribuição por grupos etários.

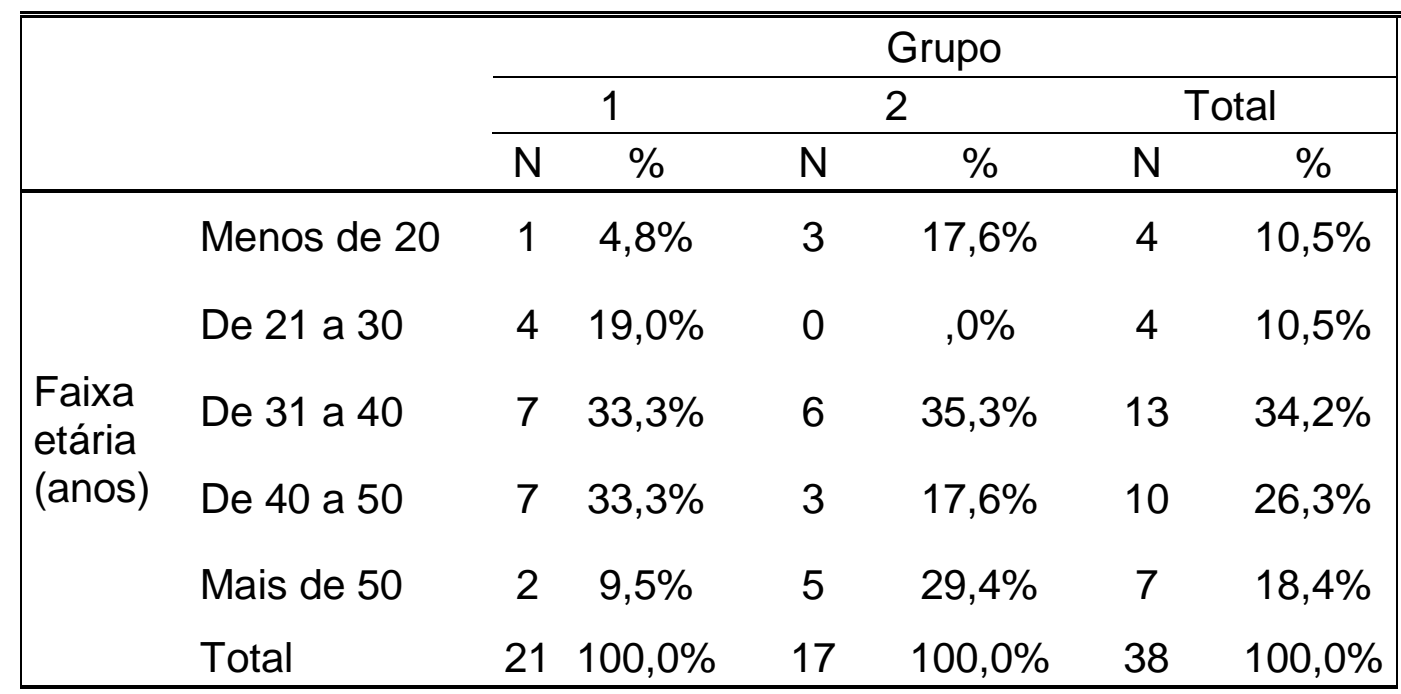


Tabela 1. Distribuição por gênero.

\begin{tabular}{cccccccc}
\hline \hline & \multicolumn{7}{c}{ Grupo } \\
\cline { 3 - 8 } & & \multicolumn{2}{c}{1} & & 2 & \multicolumn{2}{c}{ Total } \\
\cline { 3 - 8 } & & $\mathrm{N}$ & $\%$ & $\mathrm{~N}$ & $\%$ & $\mathrm{~N}$ & $\%$ \\
\hline \multirow{3}{*}{ Sexo } & Feminino & 9 & $42,9 \%$ & 11 & $64,7 \%$ & 20 & $52,6 \%$ \\
& Masculino & 12 & $57,1 \%$ & 6 & $35,3 \%$ & 18 & $47,4 \%$ \\
& Total & 21 & $100,0 \%$ & 17 & $100,0 \%$ & 38 & $100,0 \%$ \\
\hline & & & & & & $\mathrm{p}$ & 0,18 \\
\hline
\end{tabular}

Teste qui-quadrado(x2). Diferença estatisticamente significante quando $p<0,05^{\star}$.

Tabela 2. Distribuição por lado operado.

\begin{tabular}{llcccccc}
\hline \hline & & \multicolumn{7}{c}{ Grupo } \\
\cline { 3 - 8 } & & \multicolumn{2}{c}{1} & & & 2 & \multicolumn{2}{c}{ Total } \\
\cline { 3 - 9 } & & $\mathrm{N}$ & $\%$ & $\mathrm{~N}$ & $\%$ & $\mathrm{~N}$ & $\%$ \\
\hline \multirow{2}{*}{ Orelha } & Direita & 13 & $61,9 \%$ & 8 & $47,1 \%$ & 21 & $55,3 \%$ \\
lado & Esquerda & 8 & $38,1 \%$ & 9 & $52,9 \%$ & 17 & $44,7 \%$ \\
& Total & 21 & $100,0 \%$ & 17 & $100,0 \%$ & 38 & $100,0 \%$ \\
\hline & & & & & & $\mathrm{p}$ & 0,36 \\
\hline
\end{tabular}

Teste qui-quadrado (x2). Diferença estatisticamente significante quando $p<0,05^{*}$.

\subsection{Tamanho da meatoplastia, quantidade de secreção e dificuldade na limpeza}

Os resultados da avaliação do tamanho da meatoplastia, da quantidade de material a ser removido e da dificuldade encontrada estão apresentados na tabela 3. Foi testado se essas variáveis em cada grupo diferiam entre si. Não houve diferença estatisticamente significante entre os grupos em relação a essas variáveis (meatoplastia $p=0,061$; quantidade de secreção $p=0,282$; dificuldade na limpeza $p=0,087)$. 
Tabela 3. Tamanho da meatoplastia, quantidade de secreção e dificuldade na limpeza.

\begin{tabular}{|c|c|c|c|c|c|c|c|}
\hline & & \multicolumn{6}{|c|}{ Grupo } \\
\hline & & \multicolumn{2}{|c|}{1} & \multicolumn{2}{|r|}{2} & \multicolumn{2}{|c|}{ Total } \\
\hline & & $\mathrm{N}$ & $\%$ & $\mathrm{~N}$ & $\%$ & $\mathrm{~N}$ & $\%$ \\
\hline \multirow{5}{*}{ Meatoplastia } & Ampla & 12 & $57,1 \%$ & 8 & $47,1 \%$ & 20 & $52,6 \%$ \\
\hline & Estreita & 5 & $23,8 \%$ & 9 & $52,9 \%$ & 14 & $36,8 \%$ \\
\hline & Muito ampla & 4 & $19,0 \%$ & 0 & $0,0 \%$ & 4 & $10,5 \%$ \\
\hline & Total & 21 & $100,0 \%$ & 17 & $100,0 \%$ & 38 & $100,0 \%$ \\
\hline & & & & & & $p$ & 0,061 \\
\hline \multirow{6}{*}{$\begin{array}{l}\text { Quantidade } \\
\text { de secreção }\end{array}$} & Grande & 6 & $28,6 \%$ & 9 & $52,9 \%$ & 15 & $39,5 \%$ \\
\hline & Moderada & 6 & $28,6 \%$ & 4 & $23,5 \%$ & 10 & $26,3 \%$ \\
\hline & Pequena & 9 & $42,9 \%$ & 4 & $23,5 \%$ & 13 & $34,2 \%$ \\
\hline & Total & 21 & $100,0 \%$ & 17 & $100,0 \%$ & 38 & $100,0 \%$ \\
\hline & & & & & & $p$ & 0,282 \\
\hline & Grande & $\overline{1}$ & $4,8 \%$ & 3 & $17,6 \%$ & 4 & $10,5 \%$ \\
\hline \multirow{4}{*}{$\begin{array}{l}\text { Dificuldade } \\
\text { na limpeza }\end{array}$} & Moderada & 3 & $14,3 \%$ & 6 & $35,3 \%$ & 9 & $23,7 \%$ \\
\hline & Pequena & 17 & $81,0 \%$ & 8 & $47,1 \%$ & 25 & $65,8 \%$ \\
\hline & Total & 21 & $100,0 \%$ & 17 & $100,0 \%$ & 38 & $100,0 \%$ \\
\hline & & & & & & $\mathrm{p}$ & 0,087 \\
\hline
\end{tabular}

Teste qui-quadrado (x2). Diferença estatisticamente significante quando $p<0,05^{\star}$.

\subsection{Benefício na exposição}

No grupo 1 (microscopia-endoscopia) a avaliação com endoscopia trouxe benefício na exposição a $57,1 \%$ dos casos (12/21). Ou seja, em mais da metade dos casos o endoscópio conseguiu expor áreas não expostas com o microscópio. Já no grupo 2 (endoscopia-microscopia), a avaliação com microscopia subsequente não trouxe benefício na exposição em nenhum caso (0/17). Quando os resultados dos grupos foram comparados (tabela 4, gráfico 1 e figura 14) observou-se uma diferença estatisticamente significante $(p=0,000)$. Isso quer dizer que a endoscopia trouxe mais benefício na exposição sobre a microscopia do que o oposto. 
Tabela 4. Benefício do segundo método (grupo 1 = endoscopia; grupo 2 = microscopia) na exposição após inspeção e limpeza com o primeiro método.

\begin{tabular}{|c|c|c|c|c|c|c|c|}
\hline & & \multicolumn{6}{|c|}{ Grupo } \\
\hline & & \multicolumn{2}{|c|}{ (1) Endoscopia } & \multicolumn{2}{|c|}{ (2) Microscopia } & \multicolumn{2}{|c|}{ Total } \\
\hline & & $\mathrm{N}$ & $\%$ & $\mathrm{~N}$ & $\%$ & $\mathrm{~N}$ & $\%$ \\
\hline \multirow{3}{*}{$\begin{array}{c}\text { Trouxe } \\
\text { benefício } \\
\text { na } \\
\text { exposição }\end{array}$} & Não & $\overline{9}$ & $42,90 \%$ & 17 & $100,00 \%$ & 26 & $68,40 \%$ \\
\hline & Sim & 12 & $57,10 \%$ & 0 & $0,00 \%$ & 12 & $31,60 \%$ \\
\hline & Total & 21 & $100,00 \%$ & 17 & $100,00 \%$ & 38 & $100,00 \%$ \\
\hline
\end{tabular}

Teste qui-quadrado (x2). Diferença estatisticamente significante quando $p<0,05^{*}$.

Gráfico 1. Avaliação do benefício do segundo método (grupo 1 = endoscopia; grupo 2 = microscopia) em relação à exposição.

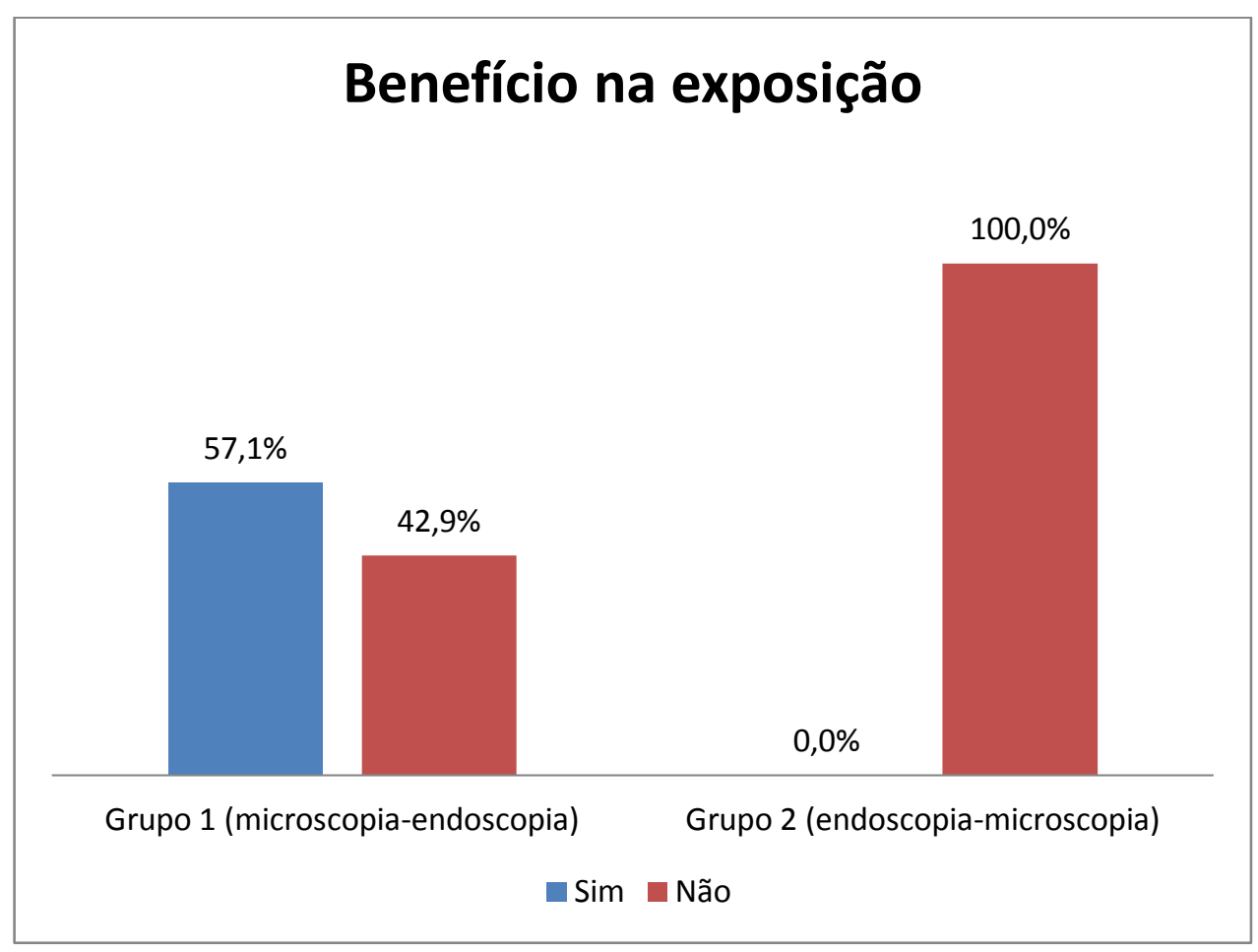




\subsection{Benefício na limpeza}

No grupo 1 a avaliação com endoscopia trouxe benefício na limpeza da cavidade em $61,9 \%$ dos casos (13/21), ou seja, em mais da metade dos casos o endoscópio permitiu remover material não removido sob microscopia. Estão juntos os casos em que esse material não foi visto com o microscópio e os casos em que foi visto, mas não foi tecnicamente possível removê-lo. Já no grupo 2, a avaliação subsequente com microscopia trouxe benefício na limpeza em $23,5 \%$ (4/17) dos casos. Quando os resultados dos grupos foram comparados observou-se uma diferença estatisticamente significante $(p=0,018)$. Isso quer dizer que a endoscopia trouxe mais benefício na limpeza sobre a microscopia do que o oposto (tabela 5 , gráfico 2 e figura 14).

Tabela 5. Benefício do segundo método (grupo 1 = endoscopia; grupo $2=$ microscopia) na limpeza após inspeção e limpeza com o primeiro método.

\begin{tabular}{|c|c|c|c|c|c|c|c|}
\hline & \multicolumn{6}{|c|}{ Grupo } \\
\hline & & \multicolumn{2}{|c|}{ (1) Endoscopia } & \multicolumn{2}{|c|}{ (2) Microscopia } & \multicolumn{2}{|c|}{ Total } \\
\hline & & $\mathrm{N}$ & $\%$ & $\mathrm{~N}$ & $\%$ & $\mathrm{~N}$ & $\%$ \\
\hline \multirow{4}{*}{$\begin{array}{c}\text { Trouxe } \\
\text { benefício } \\
\text { na } \\
\text { limpeza }\end{array}$} & Não & 8 & $38,10 \%$ & $\overline{13}$ & $76,50 \%$ & 21 & $55,30 \%$ \\
\hline & Sim & 13 & $61,90 \%$ & 4 & $23,50 \%$ & 17 & $44,70 \%$ \\
\hline & Total & 21 & $100,00 \%$ & 17 & $100,00 \%$ & 38 & $100,00 \%$ \\
\hline & & & & & & & $0,018^{*}$ \\
\hline
\end{tabular}

Teste qui-quadrado (x2). Diferença estatisticamente significante quando $p<0,05^{\star}$. 
Gráfico 2. Avaliação do benefício do segundo método (grupo 1 = endoscopia; grupo 2 = microscopia) em relação à limpeza.

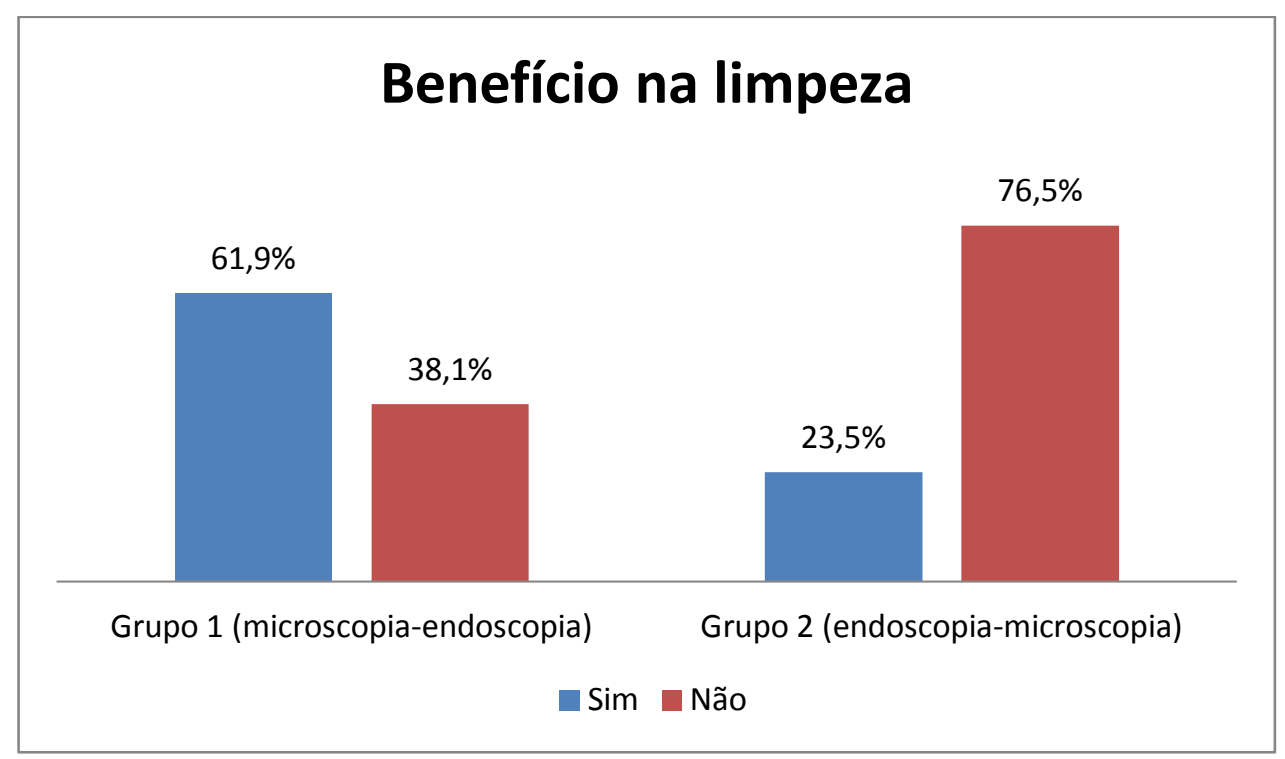

\subsection{Uso das imagens na instrução dos pacientes}

Todos os pacientes consideram que a apresentação das imagens ajudou na compreensão da doença, e $94,7 \%$ (90,5\% do grupo 1 e 100\% do grupo 2) dos pacientes consideraram que o uso das imagens fará com que aumente a aceitação e aderência ao seguimento (avaliações periódicas). Os dois únicos pacientes que não consideraram que melhorariam a adesão ao tratamento justificaram que já seguiam adequadamente as orientações (quadro 2).

Quadro 2. Resposta dos pacientes à pergunta: "O uso dessas imagens ajudará que você aceite e siga melhor o tratamento proposto?".

\begin{tabular}{|ccccccc|}
\hline \hline & \multicolumn{6}{c}{ Grupo } \\
\cline { 2 - 7 } & \multicolumn{2}{c}{1} & \multicolumn{2}{c|}{2} & \multicolumn{2}{c|}{ Total } \\
\cline { 2 - 7 } & $\mathrm{N}$ & $\%$ & $\mathrm{~N}$ & $\%$ & $\mathrm{~N}$ & $\%$ \\
\hline Não & 2 & $9,50 \%$ & 0 & $0,00 \%$ & 2 & $5,30 \%$ \\
Sim & 19 & $90,50 \%$ & 17 & $100,00 \%$ & 36 & $94,70 \%$ \\
Total & 21 & $100,00 \%$ & 17 & $100,00 \%$ & 38 & $100,00 \%$ \\
\hline
\end{tabular}




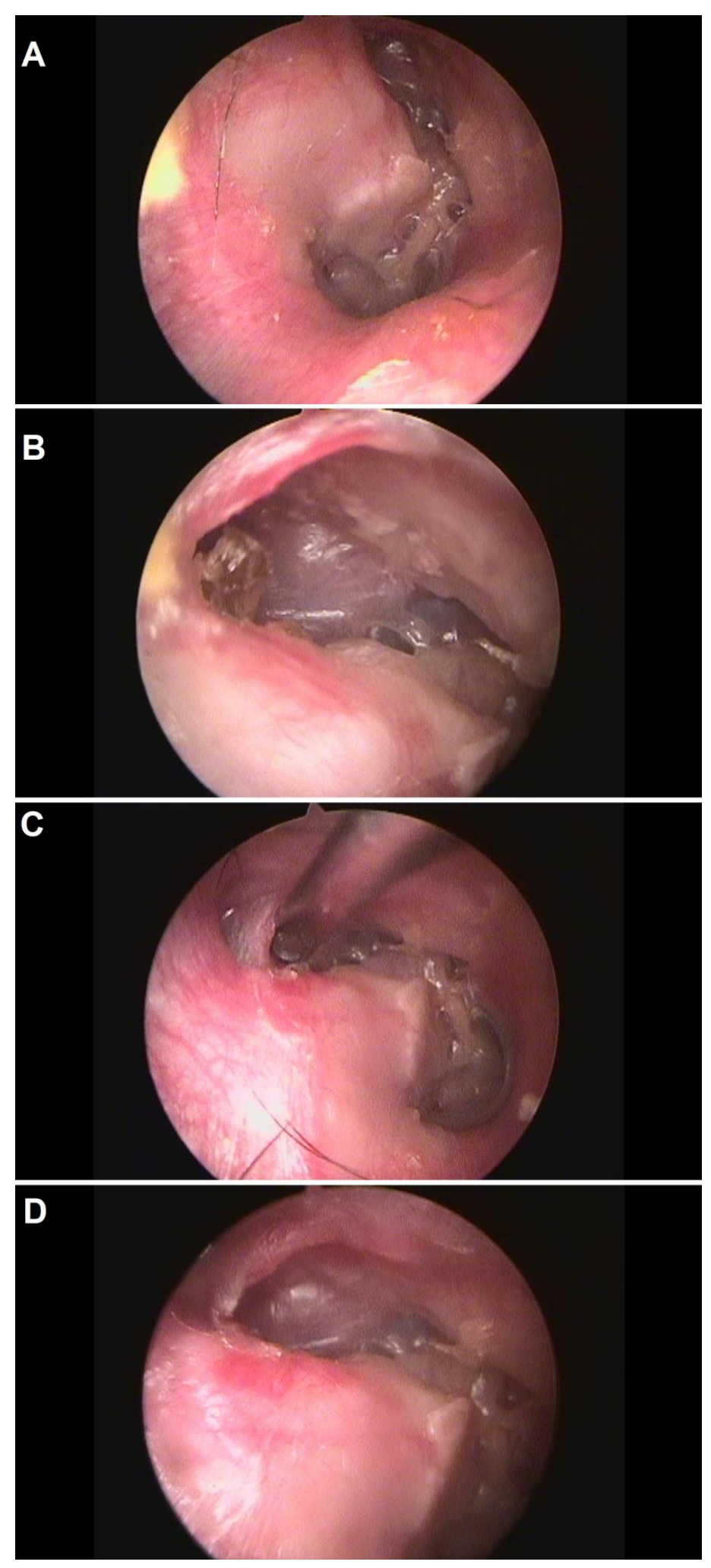

Figura 14. Inspeção e limpeza de orelha direita com endoscópio após mesma abordagem com microscópio: A limpeza com microscópio parecia ter sido completa (A). Com aproximação do endoscópio observa-se resto de material em área atrás de aderência cutânea (B). Após abordagem com endoscópio (C), observa-se cavidade limpa (D). 


\subsection{Influência das variáveis nos desfechos primários}

Foi testado se cada variável teve influência no resultado obtido em relação ao benefício na exposição e limpeza. Nenhuma das variáveis influenciou significativamente os resultados em relação ao benefício na exposição (tabela 3). Quanto ao benefício na limpeza, houve relação estatisticamente significante apenas em relação à dificuldade encontrada em realizá-la $(p=0,034)$. Quanto mais difícil foi o procedimento, menor foi o benefício encontrado (tabelas 6 e 7 ).

Tabela 6. Avaliação da relação do benefício na exposição e as variáveis: tamanho da meatoplastia, quantidade de material a ser removido e dificuldade encontrada na limpeza.

\begin{tabular}{|c|c|c|c|c|c|c|c|}
\hline & & \multicolumn{6}{|c|}{ Benefício na exposição } \\
\hline & & \multicolumn{2}{|c|}{ Não } & \multicolumn{2}{|c|}{ Sim } & \multicolumn{2}{|c|}{ Total } \\
\hline & & $\mathrm{N}$ & $\%$ & $\mathrm{~N}$ & $\%$ & $\mathrm{~N}$ & $\%$ \\
\hline \multirow{5}{*}{ Meatoplastia } & Ampla & 13 & $50,0 \%$ & 7 & $58,3 \%$ & 20 & $52,6 \%$ \\
\hline & Estreita & 10 & $38,5 \%$ & 4 & $33,3 \%$ & 14 & $36,8 \%$ \\
\hline & $\begin{array}{l}\text { Muito } \\
\text { ampla }\end{array}$ & 3 & $11,5 \%$ & 1 & $8,3 \%$ & 4 & $10,5 \%$ \\
\hline & Total & 26 & $100,0 \%$ & 12 & $100,0 \%$ & 38 & $100,0 \%$ \\
\hline & & & & & & $p$ & 0,884 \\
\hline \multirow{5}{*}{$\begin{array}{l}\text { Quantidade } \\
\text { de secreção }\end{array}$} & Grande & 11 & $42,3 \%$ & 4 & $33,3 \%$ & 15 & $39,5 \%$ \\
\hline & Moderada & 7 & $26,9 \%$ & 3 & $25,0 \%$ & 10 & $26,3 \%$ \\
\hline & Pequena & 8 & $30,8 \%$ & 5 & $41,7 \%$ & 13 & $34,2 \%$ \\
\hline & Total & 26 & $100,0 \%$ & 12 & $100,0 \%$ & 38 & $100,0 \%$ \\
\hline & & & & & & $p$ & 0,793 \\
\hline \multirow{5}{*}{$\begin{array}{l}\text { Dificuldade na } \\
\text { limpeza }\end{array}$} & Grande & 4 & $15,4 \%$ & 0 &, $0 \%$ & 4 & $10,5 \%$ \\
\hline & Moderada & 8 & $30,8 \%$ & 1 & $8,3 \%$ & 9 & $23,7 \%$ \\
\hline & Pequena & 14 & $53,8 \%$ & 11 & $91,7 \%$ & 25 & $65,8 \%$ \\
\hline & Total & 26 & $100,0 \%$ & 12 & $100,0 \%$ & 38 & $100,0 \%$ \\
\hline & & & & & & $p$ & 0,068 \\
\hline
\end{tabular}

Teste qui-quadrado (x2). Diferença estatisticamente significante quando $\mathrm{p}<0,05^{\star}$. 
Tabela 7. Avaliação da relação do benefício na limpeza e as variáveis: tamanho da meatoplastia, quantidade de material a ser removido e dificuldade encontrada na limpeza.

\begin{tabular}{|c|c|c|c|c|c|c|c|}
\hline & & \multicolumn{6}{|c|}{ Benefício na limpeza } \\
\hline & & \multicolumn{2}{|c|}{ Não } & \multicolumn{2}{|c|}{ Sim } & \multicolumn{2}{|c|}{ Total } \\
\hline & & $\mathrm{N}$ & $\%$ & $N$ & $\%$ & $\mathrm{~N}$ & $\%$ \\
\hline \multirow{5}{*}{ Meatoplastia } & Ampla & 12 & $57,1 \%$ & 8 & $47,1 \%$ & 20 & $52,6 \%$ \\
\hline & Estreita & 6 & $28,6 \%$ & 8 & $47,1 \%$ & 14 & $36,8 \%$ \\
\hline & $\begin{array}{l}\text { Muito } \\
\text { ampla }\end{array}$ & 3 & $14,3 \%$ & 1 & $5,9 \%$ & 4 & $10,5 \%$ \\
\hline & Total & 21 & $100,0 \%$ & 17 & $100,0 \%$ & 38 & $100,0 \%$ \\
\hline & & & & & & $p$ & 0,431 \\
\hline \multirow{5}{*}{$\begin{array}{l}\text { Quantidade de } \\
\text { secreção }\end{array}$} & Grande & 9 & $42,9 \%$ & 6 & $35,3 \%$ & 15 & $39,5 \%$ \\
\hline & Moderada & 4 & $19,0 \%$ & 6 & $35,3 \%$ & 10 & $26,3 \%$ \\
\hline & Pequena & 8 & $38,1 \%$ & 5 & $29,4 \%$ & 13 & $34,2 \%$ \\
\hline & Total & 21 & $100,0 \%$ & 17 & $100,0 \%$ & 38 & $100,0 \%$ \\
\hline & & & & & & $p$ & 0,526 \\
\hline \multirow{5}{*}{$\begin{array}{l}\text { Dificuldade na } \\
\text { limpeza }\end{array}$} & Grande & 0 &, $0 \%$ & 4 & $23,5 \%$ & 4 & $10,5 \%$ \\
\hline & Moderada & 7 & $33,3 \%$ & 2 & $11,8 \%$ & 9 & $23,7 \%$ \\
\hline & Pequena & 14 & $66,7 \%$ & 11 & $64,7 \%$ & 25 & $65,8 \%$ \\
\hline & Total & 21 & $100,0 \%$ & 17 & $100,0 \%$ & 38 & $100,0 \%$ \\
\hline & & & & & & $p$ & $0,034^{*}$ \\
\hline
\end{tabular}

Teste qui-quadrado (x2). Diferença estatisticamente significante quando $p<0,05^{\star}$. 


\section{DISCUSSÃO}

Esses resultados demonstram que, para cuidados ambulatoriais em pósoperatório de mastoidectomia com cavidade aberta, o endoscópio tem mais benefícios em relação ao microscópio do que o oposto. Em mais da metade dos casos $(57,1 \%)$ o endoscópio conseguiu expor áreas não expostas com o microscópio. Além disso, em quase dois terços dos casos $(61,9 \%)$ o endoscópio permitiu remover material não removido sob microscopia. De acordo com esses resultados, utilizar o endoscópio para inspeção e limpeza de cavidades demonstrou ser um método eficaz e mais eficiente quando comparado com o método padrão (microscopia). Isto sugere que o endoscópio poderia substituir o microscópio sem prejuízo na maioria das situações. Mais do que isso, a otoendoscopia foi superior à microscopia na exposição e limpeza. Com uma melhor exposição é possível uma melhor limpeza ${ }^{2-4}$ (figura 14).

A única variável que teve influência significativa nos benefícios foi a dificuldade encontrada na realização da limpeza. Quanto mais difícil, menor foi o benefício, não importando qual era o segundo método. Provavelmente isso seja devido à dificuldade e limitação encontrada na avaliação e limpeza de cavidades com meatoplastias muito estreitas. $O$ endoscópio precisa de pelo menos $4 \mathrm{~mm}$ para a sua passagem, sem contar no espaço das pinças ou aspirador. Quando menor a abertura, menor será o espéculo adequado, o que por sua vez reduz ainda mais o campo de visão e o de trabalho. No entanto, não foi encontrada relação estatística com o tamanho da meatoplastia. A determinação do tamanho da meatoplastia pode ter sido comprometida pela subjetividade da avaliação dessa característica.

O endoscópio permite transferir a fonte de luz para dentro da cavidade a despeito do tamanho da abertura externa da orelha. Associado ao campo amplo, isso permite uma visão global e mais ampla, inclusive dos recessos e cantos de difícil acesso. Já a microscopia usa uma fonte de luz projetada do lado de fora. Assim o acesso da luz é muito limitado pela abertura externa do CAE e da meatoplastia.

A limitação ao uso de apenas uma das mãos para manipular as cavidades sob otoendoscopia não trouxe prejuízo significativo como se poderia imaginar. A 
visão mais ampla e global da cavidade permitiu manipular o material de forma adequada, mesmo com uma única mão.

Os pacientes se mostraram satisfeitos com a avaliação combinada e relataram, quase com unanimidade, que a apresentação das imagens fez com que eles compreendessem melhor sua doença e que se propusessem a aderir melhor ao tratamento. A literatura reforça o papel do uso da otoendoscopia ${ }^{11} \mathrm{com}$ sistemas de gravação de imagens e outras mídias ${ }^{12}$ na educação de pacientes em relação a sua doença. Além disso, a obtenção de imagens tem grande aplicabilidade no treinamento médico.

Não foi avaliado se a vantagem de cada método trouxe algum benefício clínico (por exemplo, diminuição de sintomas ou de infecções). O objetivo do trabalho era avaliação da aplicabilidade da otoendoscopia em fazer o que já se fazia sob microscopia. A persistência de resíduos na cavidade mastóidea pode propiciar a persistência do processo infeccioso. Neste caso, a melhor remoção destes resíduos, quando utilizada a otoendoscopia, poderia contribuir para um melhor controle clínico destes pacientes.

O fato de o primeiro avaliador saber que o segundo faria uma nova avaliação (mesmo não sabendo o desenho e os detalhes do estudo) poderia ser um viés. $O$ primeiro avaliador poderia fazer uma limpeza menos meticulosa sabendo que haveria uma nova avaliação. No entanto, isto gerou um efeito positivo de "ser observado" (efeito Hawthorne). Ou seja, o trabalho do primeiro avaliador estava sendo avaliado pelo segundo, logo a tendência é que a limpeza tenha sido feita com mais rigor. Dessa forma, esse possível viés foi minimizado.

No grupo 1 o rinologista (fellow) avaliou o trabalho do otologista (fellow). O rinologista, em geral, tem mais familiaridade com o endoscópio do que com o microscópio. Diante disto, o rinologista poderia ser tendencioso a valorizar mais os resultados do endoscópio, principalmente porque o pesquisador responsável é o fellow em rinologia. No entanto, no grupo 2 o oposto ocorreu e o otologista avaliou o trabalho do rinologista. Temos então tendências opostas em cada avaliador. Estas tendências poderiam anular-se mutuamente e minimizar o viés. 
Os resultados com a otoendoscopia poderiam ter sido melhores se utilizados melhores equipamentos. O endoscópio utilizado foi o mesmo usado para avaliação nasal (4 mm de diâmetro e $165 \mathrm{~mm}$ de comprimento, 0ำ de angulação) devido a sua grande disponibilidade nos centros de atendimento otorrinolaringológico. O sistema de vídeo não era full HD, então a definição da imagem do microscópio era superior (por não depender da resolução da câmera e monitor). Os sistemas de vídeo com alta definição (realidade nos centros cirúrgicos) devem aumentar sua disponibilidade nos consultórios dentro de pouco tempo. O preço ainda é uma limitação. As pinças e os aspiradores foram os mesmos utilizados rotineiramente sob microscopia. Nos casos em que não foi possível remover todo o material sob endoscopia, geralmente o empecilho era a dificuldade de manipulação das pinças devido ao espaço ocupado pelo endoscópio. Provavelmente isso possa ser minimizado utilizando endoscópios mais finos e com campo amplo (como já é utilizado por alguns otologistas) e pinças projetadas para endoscopia. Isso melhoraria o espaço para as pinças sem prejudicar o campo.

Apesar do grande crescimento da otoendoscopia nas últimas décadas, muitos otologistas têm resistência em sua utilização no dia a dia (em cirurgias ou no consultório). Não havendo desta forma incentivo ao treinamento em otoendoscopia. Diante disso, tem-se questionado sobre como o uso do microscópio (e suas limitações) tem ditado a percepção clínica e o manejo das doenças otológicas. A visão mais ampla do endoscópio tem melhorado a compreensão sobre as doenças do ouvido e de como elas progridem no osso temporal ${ }^{2}$.

A otoendoscopia demanda treinamento e isso deve ser enfrentado pelos cirurgiões de ouvido. O manejo ambulatorial pós-operatório rotineiro pode ser uma forma de treinamento contínuo desses profissionais. Dessa forma, pode auxiliar na curva de aprendizado, proporcionando benefício para o cirurgião e para o paciente. 


\section{CONCLUSÃO}

O uso da otoendoscopia no cuidado pós-operatório de pacientes submetidos à mastoidectomia com cavidade aberta é eficaz.

A otoendoscopia trouxe mais vantagens na exposição e limpeza do que a microscopia. A otoendoscopia pode ser utilizada para esses cuidados com resultados pelo menos semelhantes aos do microscópio. Devendo ainda ser utilizada de forma complementar sempre que possível.

De forma geral, as variáveis avaliadas (tamanho da meatoplastia, quantidade de material a ser removido e dificuldade encontrada na limpeza) não influenciaram significativamente $\mathrm{o}$ benefício na exposição. A única variável que apresentou influência significativa sobre o benefício na limpeza foi a dificuldade encontrada na limpeza. Houve uma relação inversa, ou seja, quanto maior a dificuldade, menor foi o benefício, independente do método.

Os pacientes relataram um benefício subjetivo na compreensão da doença e adesão ao tratamento. 


\section{REFERÊNCIAS}

1. Mer SB, Derbyshire AJ, Brushenko A, et al. Fiberoptic endoscopes for examining the middle ear. Arch Otolaryngol 1967;85: 387-93

2. Tarabichi M, Nogueira JF, Marchioni D, Presutti L, Pothier DD, Ayache S. Transcanal endoscopic management of cholesteatoma. Otolaryngol Clin North Am. 2013 Apr;46(2):107-30.

3. El-Meselaty K, Badr-El-Dine M, Mandour M, Mourad M, Darweesh R. Endoscope affects decision making in cholesteatoma surgery. Otolaryngol Head Neck Surg. 2003 Nov;129(5):490-6.

4. Rehl RM, Oliaei S, Ziai K, Mahboubi H, Djalilian HR. Tympanomastoidectomy with otoendoscopy. Ear Nose Throat J. 2012 Dec;91(12):527-32.

5. Kakehata S, Futai K, Sasaki A, Shinkawa H. Endoscopic Transtympanic Tympanoplasty in the Treatment of Conductive Hearing Loss: Early Results. Otology \& Neurotology. 2005. 27:14-19.

6. Tarabichi M. Endoscopic middle ear surgery. Ann Otol Rhinol Laryngol 1999;108:39-46.

7. Nogueira Júnior JF, Martins MJ, Aguiar CV, Pinheiro Al. Fully endoscopic stapes surgery (stapedotomy): technique and preliminary results. Braz J Otorhinolaryngol. 2011 Nov-Dec;77(6):721-7

8. Furukawa $\mathrm{T}$, Watanabe $\mathrm{T}$, Ito $\mathrm{T}$, Kubota $\mathrm{T}$, Kakehata $\mathrm{S}$. Feasibility and Advantages of Transcanal Endoscopic Myringoplasty.Otology \& Neurotology 2014; 35:e140Ye145

9. Sadé J. Surgical planning of the treatment of cholesteatoma and postoperative follow-up. Ann Otol Rhinol Laryngol. 2000 Apr;109(4):372-6.

10. HS, Windle-Taylor PC. Canal wall down mastoidectomy: a long term commitment to the outpatients? BMC Ear, Nose and Throat Disorders 2003;3:1.

11. Jones WS. Video otoscopy: Bringing otoscopy out of the "black box". International Journal of Pediatric Otorhinolaryngology (2006) 70, 1875-1883 
12. Brock TP, Smith SR. Using digital videos displayed on personal digital assistants (PDAs) to enhance patient education in clinical settings. International journal of medical informatics. 2007 Nov-Dec;76(11-12):829-35. Epub 2006 Nov 17.

13. Hawke M. Telescopic otoscopy and photography of the tympanic membrane. J Otolaryngol 1982;11:35-9.

14. Eichner H. A new optical system in tympanic membrane and middle ear endoscopy. Endoscopy. 1981 Sep;13(5):211-3.

15. Nomura Y. Effective photography in otolaryngology-head and neck surgery: endoscopic photography of the middle ear. Otolaryngol Head Neck Surg. 1982 JulAug;90(4):395-8.

16. Takahashi H, Honjo I, Fujita A, et al. Transtympanic endoscopic findings in patientswith otitis media with effusion. Arch Otolaryngol Head Neck Surg 1990;116: 1186-9.

17. Thomassin JM, Korchia D, Doris JM. Endoscopic-guided otosurgery in the prevention of residual cholesteatomas. Laryngoscope 1993;103:939-43.

18. Poe DS, Bottrill ID. Comparison of endoscopic and surgical explorations for perilymphatic fistulas. Am J Otol 1994;15:735-8.

19. Badr-el-Dine M. Value of ear endoscopy in cholesteatoma surgery. Otol Neurotol 2002;23:631-5.

20. Yung MW. The use of middle ear endoscopy: has residual cholesteatoma been eliminated? J Laryngol Otol 2001;115:958-61.

21. Ayache S, Tramier B, Strunski V. Otoendoscopy in cholesteatoma surgery of the middle ear. What benefits can be expected? Otol Neurotol 2008;29(8):1085-90.

22. Abdel Baki F, Badr-El-Dine M, El Saiid I, et al. Sinus tympani endoscopic anatomy. Otolaryngol Head Neck Surg 2002;127:158-62.

23. Mattox DE. Endoscopy-assisted surgery of the petrous apex. Otolaryngol Head Neck Surg 2004;130:229-41. 
24. Kakehata S, Futai K, Kuroda R, et al. Office-based endoscopic procedure for diagnosis in conductive hearing loss cases using OtoScan Laser-Assisted Myringotomy. Laryngoscope 2004;114(7):1285-9.

25. Kakehata S, Hozawa K, Futai K, et al. Evaluation of attic retraction pockets by microendoscopy. Otol Neurotol 2005;26(5):834-7.

26. Kakehata S, Futai K, Sasaki A, et al. Endoscopic transtympanic tympanoplasty in the treatment of conductive hearing loss: early results. Otol Neurotol 2006;27(1): 149.

27. Magnan J, Sanna M. Endoscopy in neuro-otology. Stuttgart (Germany): Georg Thieme Verlag; 2003.

28. Badr-El-Dine M, El-Garem HF, Talaat AM, et al. Endoscopically assisted minimally invasive microvascular decompression of hemifacial spasm. Otol Neurotol 2002; 23:122-8.

29. Badr-El-Dine M, El-Garem HF, El-Ashram Y, et al. Endoscope assisted minimal invasive microvascular decompression of hemifacial spasm. Abstracts of the 9th International Facial Nerve Symposium. Otol Neurotol 2002;23(Suppl 3):68-72.

30. El-Garem HF, Badr-El-Dine M, Talaat AM, et al. Endoscopy as a tool in minimally invasive trigeminal neuralgia surgery. Otol Neurotol 2002;23:132-5.

31. McKennan KX. Endoscopic 'second look' mastoidoscopy to rule out residual epitympanic/mastoid cholesteatoma. Laryngoscope 1993;103:810-4.

32. Presutti L, Marchioni D, Mattioli F, et al. Endoscopic management of acquired cholesteatoma: our experience. Otolaryngol Head Neck Surg 2008;37(4):1-7.

33. Marchioni D, Mattioli F, Ciufelli MA, et al. Endoscopic approach to tensor fold in patients with attic cholesteatoma. Acta Otolaryngol 2008;19:1-9.

34. Tarabichi M, Ayache S, Nogueira JF, Al Qahtani M, Pothier DD. Endoscopic management of chronic otitis media and tympanoplasty. Otolaryngol Clin North Am. 2013 Apr;46(2):155-63. 
35. Tarabichi M, Marchioni D, Presutti L, Nogueira JF, Pothier D. Endoscopic transcanal ear anatomy and dissection. Otolaryngol Clin North Am. 2013 Apr;46(2):131-54.

36. Marchioni D, Alicandri-Ciufelli M, Mattioli F, Nogeira JF, Tarabichi M, Villari D, Presutti L. From external to internal auditory canal: surgical anatomy by an exclusive endoscopic approach. Eur Arch Otorhinolaryngol. 2013 Mar;270(4):1267-75.

37. Marchioni D, Alicandri-Ciufelli M, Piccinini A, Genovese E, Monzani D, Tarabichi M, Presutti L. Surgical anatomy of transcanal endoscopic approach to the tympanic facial nerve. Laryngoscope. 2011 Jul;121(7):1565-73.

38. Tarabichi M. Transcanal endoscopic management of cholesteatoma. Otol Neurotol. 2010 Jun;31(4):580-8.

39. Tarabichi M. Endoscopic transcanal middle ear surgery. Indian J Otolaryngol Head Neck Surg. 2010 Jan;62(1):6-24.

40. Tarabichi M. Endoscopic management of limited attic cholesteatoma. Laryngoscope. 2004 Jul;114(7):1157-62.

41. Tarabichi M. Endoscopic management of cholesteatoma: long-term results. Otolaryngol Head Neck Surg. 2000 Jun;122(6):874-81.

42. Tarabichi M. Endoscopic management of acquired cholesteatoma. Am J Otol. 1997 Sep;18(5):544-9.

43. Proctor B. Chronic otitis media and mastoiditis. In: Paparella MM, Schumrick DA, eds. Otolaryn- gology. Philadelphia: W.B. Saunders Comp 1973; 121-152. 29.

44. Junh SK, Paparella MM, Kim LS, et al. Pathogenesis of otitis media. Ann Otol Rhinol Laryngol. 1977;86(4):481-93

45. da Costa SS, Paparella MM, Schachern PA, et al: Temporal bone histopathology in chronically infected ears with intact and perforated tympanic membranes. Laryngoscope 1992; 102:1229-1236.

46. Cruveilhier LJB: Anatomie Pathologique du Corpus Hamani, Vol 1. Paris, JB Balliere, 1829 
47. Müller J: Über den Feineren Bau und die Formen der Krankhaften Geschwülste. Berlin, Reimer G, 1838.

48. In: Hildmann H, Sudhoff H, ed. Middle Ear Surgery, New York: Springer Verlag; 2006

49. Kinney SE. Intact canal wall tympanoplasty with mastoidectomy for cholesteatoma: long term follow up. Laryngoscope 1988;98:1190-4.

50. Tos M, Lau T. Late results of surgery in different cholesteatoma types. ORL 1989;51:33-49.

51. Jansen CW. Intact canal wall for cholesteatoma. Am J Otol 1985;6:3-4. 


\section{APÊNDICE}

\subsection{Apêndice 1 - Termo de Consentimento}

\section{Termo de Consentimento Livre e Esclarecido - TCLE}

O (a) Senhor (a) está sendo convidado (a) a participar do projeto: "Avaliação do uso de endoscópio no seguimento pós-operatório de pacientes submetidos à mastoidectomia com cavidade aberta".

O objetivo desta pesquisa é determinar a utilidade da otoendoscopia (avaliação do ouvido com sistema de vídeo) no acompanhamento após a cirurgia.

O (a) senhor (a) receberá todos os esclarecimentos necessários antes e no decorrer da pesquisa e the asseguramos que seu nome não aparecerá, sendo mantido o mais rigoroso sigilo, através da omissão total de quaisquer informações que permitam identificá-lo (a).

A sua participação será através de um questionário que o senhor (a) responderá após a limpeza do ouvido do lado operado. Após a limpeza, seu ouvido deverá ser examinado com um sistema de vídeo-endoscopia. Esse exame não the causará nenhum risco ou prejuízo. Com essa avaliação adicional, possivelmente poderemos the proporcionar o benefício de uma limpeza mais completa da região operada, o que é importante para uma cicatrização adequada e para evitar infecções.

Informamos que o (a) Senhor (a) pode se recusar a responder ou participar do procedimento, ou de qualquer questão que the traga constrangimento, podendo desistir de participar da pesquisa em qualquer momento sem nenhum prejuízo para o (a) senhor (a). Sua participação é voluntária, isto é, não há pagamento por sua colaboração. 
Os resultados da pesquisa serão divulgados na Universidade de Brasília podendo ser publicados posteriormente. Os dados e materiais utilizados na pesquisa ficarão sobre a guarda do pesquisador.

Se o (a) Senhor (a) tiver qualquer dúvida em relação à pesquisa, por favor telefone para: Dr. Gustavo Subtil Magalhães Freire, Hospital Universitário de Brasília, telefone: (61) 3448-5580. Também poderá entrar em contato com o Comitê de Ética em Pesquisa da Faculdade de Medicina da Universidade de Brasília pelo telefone (61) 3107-1918 ou no endereço: Campus Universitário Darcy Ribeiro - Asa Norte-CP- 4569 , CEP: 70.910-900 - Brasília - DF - Brasil.

Este documento foi elaborado em duas vias, uma ficará com o pesquisador responsável e a outra com o paciente.

Nome / assinatura

Pesquisador Responsável

Gustavo Subtil Magalhães Freire

Brasília, de de 


\subsection{Apêndice 2 - Questionários}

\subsubsection{Questionário 1}

Questionário 1 (respondido pelo primeiro examinador)

1 - Você considera a meatoplastia do paciente:
( ) estreita/estenosada
( ) ampla
( ) muito ampla?

2 - O paciente apresenta em sua cavidade:
( ) crostas
( ) secreção sero-purulenta
( ) outros (especifique)

3 - A quantidade de material a ser removido é:
( ) pequena
( ) moderada
( ) grande

4 - Qual a dificuldade encontrada na inspeção e limpeza realizada?
( ) pequena
( ) moderada
( ) grande

5 - A visibilização de todas as regiões de interesse foi:
( ) parcial
( ) completa

6 - Você julga que a limpeza realizada foi:

( ) parcial ( ) completa 


\subsubsection{Questionário 2}

\section{Questionário 2 (respondido pelo segundo examinador)}

1 - A visibilização de todas as regiões de interesse foi:

( ) parcial ( ) completa

2 - Havia material a ser removido?

( ) $\operatorname{sim}$ ( ) não

3 - A quantidade de material a ser removido é:
( ) pequena
( ) moderada
( ) grande

4 - O material restante estava localizado em que região?

5 - Foi possível remover o material identificado?
( ) sim - totalmente
( ) sim - parcialmente ( )não

6 - Qual a dificuldade encontrada na inspeção e limpeza realizada?
( ) pequena
( ) moderada
( ) grande

7 - Você julga que a limpeza realizada foi:

( ) parcial ( ) completa 


\subsubsection{Questionário 3}

\section{Questionário 3 (respondido pelo paciente)}

1 - O uso dessas imagens ajudou a melhorar sua compreensão sobre sua doença?

( ) $\operatorname{sim} \quad$ ( ) não

2 - O uso dessas imagens ajudará que você aceite e siga melhor o tratamento proposto?
( ) $\operatorname{sim}$
( ) não 